This item was submitted to Loughborough's Research Repository by the author.

Items in Figshare are protected by copyright, with all rights reserved, unless otherwise indicated.

\title{
The rules of engagement: how to motivate consumers to engage with branded mobile apps
}

PLEASE CITE THE PUBLISHED VERSION

https://doi.org/10.1080/0267257X.2018.1544167

\section{PUBLISHER}

(c) Westburn Publishers Ltd. Published by Taylor \& Francis (Routledge)

\section{VERSION}

AM (Accepted Manuscript)

\section{PUBLISHER STATEMENT}

This is an Accepted Manuscript of an article published by Taylor \& Francis in Journal of Marketing Management on 19 November 2018, available online:

http://www.tandfonline.com/10.1080/0267257X.2018.1544167.

\section{LICENCE}

CC BY-NC-ND 4.0

\section{REPOSITORY RECORD}

Stocchi, L., Nina Michaelidou, Naser Pourazad, and Milena Micevski. 2018. "The Rules of Engagement: How to Motivate Consumers to Engage with Branded Mobile Apps". Loughborough University.

https://hdl.handle.net/2134/35754. 


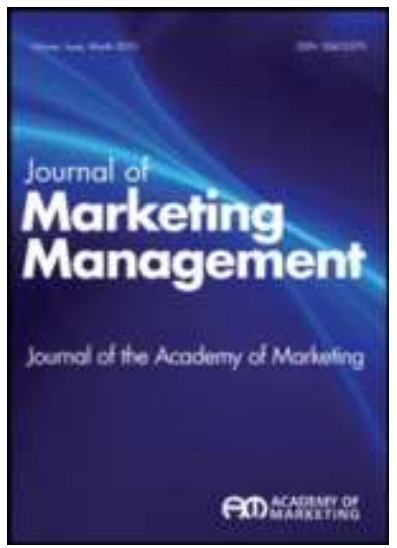

\section{The Rules of Engagement: How to Motivate Consumers to Engage with Branded Mobile Apps}

\begin{tabular}{|r|l|}
\hline Journal: & Journal of Marketing Management \\
\hline Manuscript ID & RJMM-2018-0023.R2 \\
\hline Manuscript Type: & Original Paper \\
\hline Keywords (headings not \\
selectable): & $\begin{array}{l}\text { New media < E-marketing, Technology < Innovation and } \\
\text { entrepreneurship, Consumer psychology < Consumer research }\end{array}$ \\
\hline Methodologies: & mixed method, structural equation modelling (SEM) \\
\hline Free Response Keywords: & Mobile applications, consumer engagement \\
\hline & \\
\hline
\end{tabular}

SCHOLARONE

Manuscripts 


\title{
The Rules of Engagement:
}

\section{How to Motivate Consumers to Engage with Branded Mobile Apps}

\begin{abstract}
Combining qualitative and quantitative insights, this research presents and validates a framework, which illustrates how to motivate consumers to engage with branded mobile applications, or apps. The framework shows that consumer involvement with branded apps underpins two sets of consumer perceptions of the benefits that the app offers, which reflect the different motives for engaging with the app, as consumers experience them. These perceptions include the utilitarian motives of security, usefulness and ease of use; and the hedonic motives of interpersonal utility, attachment (with the device) and entertainment. This range of motives leads to two key outcomes, i.e. the willingness to pay for the app (including in-app purchases) and the willingness to recommend the app. As a result, this research contributes to marketing research and theory by clarifying specific details of the psychological process through which it is possible to motivate consumer engagement with branded apps - i.e. by means of binding involvement, perceptions of how apps' benefits meet individual needs (and resulting experiences for consumers) and a couple of key outcomes crucial to the success of apps. The findings also yield managerial relevance. Above all, the outcomes of this research suggest that, by involving and motivating consumers through the improvement of the benefits that a branded app offers, it is possible to increase the app's revenues and to encourage word-of-mouth, creating value for app providers and consumers.
\end{abstract}

Key words: Mobile applications, consumer engagement, consumer involvement, motivation, willingness to pay, word-of-mouth.

Statement of contribution: This work advances theoretical knowledge concerning branded mobile apps by revealing how to motivate consumers to engage with apps, in order to generate relevant outcomes such as in-app purchases and word-of-mouth. This research also yields several practical implications for managers, because it illustrates how firms can leverage 
branded apps to reach large masses of consumers, engage them, and create and share value seamlessly.

\section{Introduction}

To date, there are approximately 3.8 million apps available to consumers via the Google Play Store (Statista, 2018). Consumers spend, on average, $90 \%$ of their time while operating their mobile devices using apps for a variety of purposes (e.g., accessing music, lifestyle coaching, shopping, productivity etc., see SmartInsights, 2018). Therefore, it is not surprising to find apps, especially branded ones (see Bellman, Treleaven-Hassard, Robinson, \& Varan, 2011), at the heart of current strategies by which marketers reach and engage consumers.

As apps become more and more embedded in the life of consumers, making all sorts of products and services available at little or no cost (Kim, Ling, \& Sung, 2013; Wang, Kim, \& Malthouse, 2016) and functioning as 'brand in the hand' (Sultan \& Rohm, 2005), it is paramount to understand which outcomes could be achieved (e.g., word-of-mouth recommendation and willingness to pay) and how (i.e., which benefits apps need to offer to consumers). There is a baseline consensus that mobile apps adoption and use positively impact the opportunity to engage and retain consumers (Viswanathan et al., 2017), translating into cost-effective opportunities for firms to attain specific marketing objectives, such as persuasion (Bellman et al., 2011). This is due, at least in part, to the fact that apps have extended significantly the ways through which firms engage with consumers and continue to experience substantial innovation, fuelled also by the acquisition of large sets of data (Viswanathan et al., 2017). This implies a greater likelihood for frequent and highly involving interactions between the consumer and the technology, which should facilitate the attainment of engagement. In fact, Tarute, Nikou, and Gatautis (2017) have recently argued that apps could be considered the new face of consumer engagement. More 
generally, it is widely accepted that mobile technologies are a powerful strategic tool for the attainment of desirable outcomes such as consumer engagement (Viswanathan et al., 2017). Insights into consumer engagement with apps can be derived, at least in part, from literature on post-adoption outcomes. However, the most explicit attempts to formally examine consumer engagement for mobile technologies and/or apps share some inherent limitations that hinder the understanding of how engagement works, especially for branded apps. Above all, consumer engagement and the resulting outcomes have been considered primarily from the perspective of the brand powering the app (rather than the app itself), and existing studies have often embraced a rather narrow conceptual and/or empirical scope. For example, E. Kim, Lin, and Sung (2013) explain that apps 'tap' into some of the key conceptual drivers of consumer engagement (i.e., vividness, novelty, motivation, control, customization, and feedback; see also O'Brien \& Toms, 2008). Yet, their work is primarily an overview of the strategies that sellers might use to engage consumers through apps, and it does not present any empirical knowledge. In terms of formal empirical evaluations, the literature has returned two contrasting standpoints on consumer engagement with mobile technologies, theorizing and appraising it either as a dynamic iterative process and behavioural manifestation (see Viswanathan et al., 2017; Tarute et al., 2017) or as a psychological state resulting from an array of experiences (see Y. H. Kim, Kim, \& Wachter, 2013). In fact, as Viswanathan et al. (2017) stress, concrete attempts to appraise consumer engagement with mobile technologies are quite limited. This leaves important basic questions unanswered, such as: 'How can consumers be motivated to engage with branded apps?' and also: 'What are the most likely outcomes of consumer engagement with branded apps? 
In an attempt to address these issues, the present research draws on existing literature on consumer engagement, conceptualized as a series of motives (higher order) and thus as a psychological (motivational) state shaped by the consumer perceptions of the benefits that branded apps offer and how such benefits meet individual needs, as experienced by the consumer. In more detail, this study draws upon the work of Calder, Isaac and Malthouse (2016) and Malthouse, Calder, S. J. Kim and Vandenbosch (2016), who theorise consumer engagement as a motivational state likely to originate from the thoughts and feelings concerning multiple rich experiences involved in the pursuit of personal goals or values. This research also draws upon earlier works on media engagement by Calder and Malthouse (2008), Calder, Malthouse, and Schaedel (2009), and Davis Mersey, Malthouse and Calder (2010), who highlight that the experiences embedded in consumer engagement are shaped by the beliefs of how the medium fits into consumers' lives by satisfying utilitarian and hedonic needs. When considering engagement as a collection of experiences (see also McCarthy \& Wright, 2004), it becomes an unobservable antecedent of outcomes such as usage, liking or intention to recommend to others (Calder \& Malthouse 2008; Calder et al. 2009). Also, in line with O'Brien and Toms (2008), it is possible to shed light on consumer engagement by means of considering the attributes of engagement, i.e. attributes that underpin engagement with a technology by enhancing consumer motivation.

The theoretical assumptions outlined above are supported by two empirical studies, using a mixed methods approach. Namely, through a qualitative study (five focus groups involving a total of 22 consumers conducted in the UK), this research first outlines a framework, which describes the characteristics of apps that are likely to motivate consumers to engage with them and the likely behavioural outcomes. This framework is then tested empirically, through a quantitative analysis of a set of consumer survey data gathered online $(N=335$, UK panel data 
accessed from a commercial provider). The results of the analysis allow exploring the link between utilitarian and hedonic motives that apps offer, and that ultimately incentivize consumers to engage with apps, leading to behavioural outcomes.

Comprehensively, the present research contributes to existing knowledge concerning the understanding of post-adoption outcomes for branded apps, as an important instance of mobile technology widely used by organisations to reach and engage consumers. In this regard, this research adds significantly to the understanding of how to motivate consumers to engage with branded apps, shedding light on a set of key conceptual assumptions concerning the provision of motivational experiences by tapping into a range of key utilitarian and hedonic benefits that branded apps can offer, meeting individual consumer needs. These insights are supported by the provision of qualitative and quantitative empirical insights for a number of popular branded apps, adding to the limited knowledge specific to consumer engagement with branded apps. The present research also makes a contribution to practice, highlighting some essential aspects that need to be taken into consideration when making branded apps available to consumers and setting strategic goals. Importantly, the originality of this research also resides in the deliberate decision to focus on the analysis of consumer engagement with the branded app itself, rather than the brand powering the app. As such, the conclusions drawn are relevant to a wider audience of practitioners - e.g., managers of apps linked to existing brands (e.g., apps linked to retailers), as well as managers of apps branded independently as 'stand-alone' digital products.

\section{Background}

Apps and consumer engagement: what do we know so far? 
Research efforts concerning mobile apps have increased dramatically over the past decade. On a broad level, existing works can be distinguished into research focusing on discovering the drivers of apps' adoption and research examining post-adoption outcomes.

Research on adoption has often focused on mobile technologies as a whole and treated mobile apps as specific instance of mobile marketing. Nonetheless, in this strand of research there are a number of key contributions, which clearly point to specific characteristics of apps likely to offer a wide range of experiences that can motivate consumers to use apps and to engage with apps. For example, Jin and Villegas (2008) looked into different types of motives (e.g., escape, information, socialization etc.) that mobile phones offer to consumers, driving usage. Kleijnen, Ruyter and Wetzels (2007) considered a range of utilitarian factors that determine the overall perceived value of mobile commerce to consumers (e.g., time convenience, user control, and service compatibility). Similarly, Yang and Jolly (2009) outlined the conceptual relationships between different types of values that mobile data services offer to consumers (e.g., functional, social, and emotional values), driving attitudes and intentions to use the technology; and Tobjib and Tsarenko (2012) linked to the delivery of experiential value to consumers certain characteristics of advanced mobile services (including apps) such as ubiquity, enjoyment and time convenience. Venkatesh, Thong, and Xu (2012) outlined a series of expectations that consumers might have in relation to mobile Internet, which ultimately drive their perceptions of value, habits and usage intentions. Ho (2012) highlighted a series of intrinsic and extrinsic drivers of the intention to use and continued usage for location-based personalised mobile data services. Finally, Bellman et al. (2011) distinguished between the experiential and informational functions of branded apps (i.e., apps clearly displaying a brand identity) and linked these aspects to the effectiveness of apps as a 'pull' advertising medium. Interestingly, none of these works 
explicitly drew on consumer engagement theory, but focussed more or less openly on two conceptual bases that firm the theoretical basis for consumer engagement: motivation theory and expectancy theory.

Y. H. Kim et al.'s (2013) study is arguably the only one concerning the adoption of mobile technologies, which has formally introduced and tested a research model explicitly predicting engagement intention - defined (and appraised) in terms of the likelihood to continue using a mobile technology, and the likelihood to recommend it. In more detail, Y. H. Kim et al. (2013) defined engagement with mobile technologies as 'the state of being involved, occupied, retained, and intrinsically interested in something' (p. 361). They also added that engagement is shaped by the on-going activities (or behavioural flow), attitudes, and the intrinsic interest of the experience resulting from the characteristics of mobile technologies (e.g., novelty, interactivity, perceived user control etc.). Nonetheless, Y. H. Kim et al. focussed on mobile technologies as a whole, rather than apps or branded apps.

Apps differ from the more generic array of mobile technologies in multiple ways, especially if inherently branded (see Bellman et al. 2011). Above all, they offer many additional opportunities in terms of consumer engagement (see E. Kim et al., 2013; Seitz \& Aldebasi, 2016; Wang et al., 2016) and the establishment of customer relationship management strategies (see Morosan \& DeFranco, 2015; 2016). This is perhaps the reason why, within the stream of literature that has focused on post-adoption of mobile technologies, the emphasis on consumer engagement is much more obvious. Yet, as explained next, there are some inherent limitations, which shaped the rationale of the present research.

First, similar to research on adoption, several works do not explicitly talk about engagement and have focused on other theoretical bases, such as motivation theory (e.g., Choi, 
Y. Kim, \& Kim, 2011; Alnawas \& Aburub, 2016; Kim \& Ah Yu, 2016). Many works also considered consumer engagement with apps in general, rather than focusing on specific instances of apps, especially branded ones (e.g., Jain \& Viswanathan, 2015; Dovaliene, Piligrimiene, \& Masiulyte, 2016). Second, some authors (e.g., Furner et al., 2014; Kim \& Yu, 2016; Fang, 2017) have examined consumer engagement with apps, but have conflated it with the notion of apps 'stickiness', which is an indicator of consumer loyalty towards the app or continuous use (S. J. Kim, Wang, \& Malthouse, 2015). This is concerning, given that existing research (e.g., Bowden, 2009; Hollebeek, 2011) clearly indicates that, although consumer engagement explains the process through which consumer loyalty might unfold, it is not the same as consumer loyalty. Third, several post-adoption studies often provided predictions in relation to the brand powering the app, rather than the app itself (see S. J. Kim et al., 2015 as example of empirical study; and E. Kim et al., 2013, Larivière et al., 2013, and Wang et al., 2016 as examples of conceptual studies). In light of the proliferation of successful branded apps that are not necessarily linked to any existing brand (e.g., Evernote and Spotify, just to mention two of the most popular ones), the need to research explicitly consumer engagement with individual apps (i.e., not with apps in general as instance of digital technology, and not with the brand powering the app) seems both theoretically and practically relevant.

Viswanathan et al. (2017) formally defined consumer engagement with mobile technologies as a dynamic iterative process that comprises behaviours representative of the scope of the experience with digital media. Yet, Viswanathan et al.'s (2017) work contains a couple of analytical shortcomings. First, their work is focused on the analysis of one single branded app linked to an existing loyalty program. Second, they appraised consumer engagement exclusively in relation to its concrete behavioural manifestations (i.e., recency and frequency of the app use). 
Similarly, Wu (2015) and Tarute et al. (2017) present empirical models outlining the characteristics of apps that can underline consumer engagement and the intention to continue using the app. However, they examine consumer engagement primarily as a behavioural manifestation. Arguably, the emphasis placed on the behavioural facet of consumer engagement limits the understanding of the underpinning psychological triggers, especially in relation to: i) likely antecedents; ii) different types of motivational values that branded apps offer to consumers (e.g., utilitarian and hedonic, see Jain \& Viswanathan, 2015); and iii) likely outcomes.

In light of the above, the following section outlines a series of conceptual assumptions concerning consumer engagement that have informed the present research and the design of the two studies described in detail later on. The decision to invoke consumer engagement theory, as opposed to alternative theoretical bases such as motivation theory or expectancy theory, is justified as follows. Although the basic principles of motivation and user gratification have been deployed extensively in the context of understanding the appeal of various types of media (including social media and other digital technologies - e.g. Papacharissi \& Rubin, 2000; Shao, 2008; Smock et al., 2011; Shin, 2010), some caution as been raised due to the potential risks of over-simplifying complex mechanisms, such as the likely interplay between gratification (or benefits) sought and gratification (benefits) obtained (Mondi et al., 2008). In fact, some researchers (e.g., Smock et al., 2011) have highlighted the need to use a more 'granular' approach, which takes into account the multitude of different activities and uses that a certain medium can offer. Accordingly, the present research embraces a series of specific assumptions on consumer engagement theory to further advance knowledge about branded apps.

\section{Assumptions on consumer engagement}


Thus far, the most explicit attempts to formally examine consumer engagement for mobile technologies and/or apps have returned two contrasting assumptions, theorizing it either as a dynamic iterative process and behavioural manifestation (e.g., Viswanathan et al., 2017; Tarute et al., 2017) or as a psychological state resulting from an array of experiences (e.g., Y. H. Kim et al., 2013). This disparity of views resonates with the diversity of assumptions that characterizes, more generally, research on consumer engagement. As Abdul-Ghani, Hyde and Marshall (2012) argue, this is partly due to the fact that the engagement concept has been applied to a wide and diverse range of consumption objects.

The literature that theorizes consumer engagement as an important psychological and behavioural process, considers it to be also heavily context-dependent and closely linked to market performance (Brodie, Ilic, Juric, \& Hollebeek, 2011; Gambetti \& Graffigna, 2010; Hollebeek, 2011). For example, Bowden (2009) highlights the importance of considering consumer engagement as a process by explaining how it 'traces the temporal development of loyalty' (p. 65). The assumption of the existence of a connection with market performance, in contrast, links back to the idea of behavioural activation. Namely, Gambetti and Graffigna (2010) and Hennig-Thurau et al. (2010) clarify that consumer engagement can often lead to the activation of a behavioural component, leading to concrete outcomes that are measurable and directly linkable to specific marketing tactics. Finally, in relation to the influence of the context, Hollebeek (2011) explains that consumer engagement 'unfolds by virtue of two-way interactions between the engagement subject (e.g., customer/consumer) and a specific engagement object, such as a brand [...], under particular contextual conditions' (p. 789). Moreover, Dessart, Veloutsou, and Morgan-Thomas (2016) and Maslowska, Malthouse, and Collinger (2016) 
expand this notion by clarifying that consumer engagement occurs within a certain 'ecosystem' i.e. an ensemble of actors, contexts and manifestations (see also Van Doorn et al., 2010).

These assumptions are crucial to appraising consumer engagement in relation to digital technologies such as mobile apps given: i) the involvement of multiple actors (e.g., app developer, app store, app provider or brand powering the app, the consumer himself/herself, other consumers etc.), ii) the many opportunities for value co-creation offered (e.g., through the concrete gathering and exchange of feedback from consumers); and iii) the possibility to connect consumers to the brand and the app, and to other consumers. Nonetheless, the standpoint that the present research puts forward is that a more appropriate theorization of consumer engagement in relation to branded apps should embrace the provision of a wide array of context-specific experiences that satisfy consumer needs. The reasoning behind this assumption is derived from the literature, as shown below.

Some researchers have argued that engagement can arise from rich qualitative 'felt' experiences that produce a proactive and interactive relationship with a specific engagement object (Calder \& Malthouse, 2004). These experiences reflect the individual's interaction with the product over time as a way of accomplishing personal goals (Calder \& Malthouse, 2008). In fact, Brodie et al. (2011) defined engagement as the psychological state that arises from experiences that are context-specific (i.e., domain-, category-, or brand-specific). Vivek, Beatty and Morgan (2012), and Abdul-Ghani et al. (2012) share the view that consumer motivations toward engagement depend on the value they expect to receive from the experience. Likewise, Hollebeek (2011) argues that consumer engagement reflects an individual motivational experience or state of mind, while Mollen and Wilson (2010) explain engagement with online 
and digital platforms in terms of 'telepresence' (i.e., mental state of being there, which is characterized by cognitive and sensory arousal, control and immersion).

More recently, Calder et al. (2016) and Malthouse et al. (2016) reiterate that engagement is a motivational state likely to originate from the thoughts and feelings concerning multiple rich experiences that are involved in the pursuit of personal goals or values. Also, Calder, Hollebeek and Malthouse (2018) state that experiential engaging branding is characterized by the strategic intent to develop customer experiences with a brand and its touch points, one of which is most certainly apps.

As a matter of fact, in the specific context of media engagement, Calder and Malthouse (2008), Calder et al. (2009) and Davis Mersey et al. (2010) have remarked that the collection of experiences resulting from the beliefs of how the medium fits into consumers' lives includes utilitarian and/or hedonic (i.e., intrinsic or self-centred and/or social-facing) dimensions. When configured as a collection of experiences (see also McCarthy \& Wright, 2004), engagement becomes an on-going process, rather than an outcome (see O'Brien \& Toms, 2008). Accordingly, consumer engagement should be regarded as an unobservable antecedent of outcomes such as usage, liking or intention to recommend to others (Calder \& Malthouse 2008; Calder et al. 2009). The motivational experiences that shape consumer engagement also feed into those outcomes, and can be examined to infer the characteristics that a certain engagement object (e.g., branded apps) need to have to successfully engage consumers. In fact, O'Brien and Toms (2008) talked about attributes of engagement, i.e. attributes that sustain engagement with a technology raising consumer motivation, interest, and encouragement. In this sense, one could also argue that similarly to research considering consumer engagement in contexts such as social media, the present research embraces a consumer-centric (or user-centric) approach (e.g., Muntinga, 
Moorman \& Smit, 2011). However, as opposed to focusing on discerning the different dimensions of gratification and resulting uses of a technology as vessel for brand-related interactions (see also Schivinski, Christodoulides \& Dabrowski, 2016), the present research focuses more broadly on the underlying mechanisms that shape consumer engagement as motivational (psychological) state. This is justified as follows.

Expanding upon the literature reviewed so far, it seems logical to presume that the benefits that branded apps offer should play an essential role in determining consumer engagement with the apps because by definition those benefits would: i) underpin whether consumers see any value in a certain app, and ii) shape the motivation to engage with the app upon meeting utilitarian and hedonic needs, generating a range of personal experiences. Further support to this assumption appears in the work of E. Kim et al. (2013), Y.H. Kim et al. (2013), and S.C. Kim, Yoon and Han (2014). Namely, according to E. Kim et al. (2013), apps are generally ideal for engaging consumers, given the high consumer usage of mobile devices and the high level of interactivity. These two aspects underpin consumer motivation, forming an experience that involves and occupies consumers, ultimately resulting in engagement. E. Kim et al. also highlight that apps represent a 'hub' for consumers to access a wide range of services for a variety of services anytime, anywhere, and to carry out numerous daily tasks. Moreover, in the specific instance of branded apps, it is possible to offer unique experiences to current as well as prospective customers. The provision of such unique experiences implies that firms can use apps to engage consumers. Interestingly, E. Kim et al. (2013) theorized consumer engagement as the sum of motivational experiences that the consumer has with the branded apps, which makes them involved, occupied and interested on an on-going basis. Out of these motivational experiences likely to bolster engagement, E. Kim et al. remark that two things typically resonate the most 
with consumers: i) anything that meets their personal interests and needs, directing them to specific goals, and ii) anything that enhances individualization (or personalization) and greater control - distinctions arguably akin to utilitarian and hedonic motives. In fact, according to Y. H. Kim et al. (2013), consumer engagement in mobile contexts originates from a series of cognitively driven motivations that result from a wide range of user experiences. More specifically, motivation can be classified as functional (efficiency, ease of use, saving time etc.), hedonic (fun, enjoyment, pleasure etc.) and social (desire to connect and share with others). Arguably, social motivation has hedonic connotations, given that the rewards that it yields are most certainly pleasurable. Regardless, mobile technologies encourage a wide range of user experiences, which act as functional and/or hedonic motivations, and encourage engagement by means of satisfying individual needs. Finally, S. C. Kim et al. (2014) argue that the link between consumer perceptions of apps features (or benefits) should lead to a theoretically significant connection between the app and the consumer. This connection is likely to extend from cognitive to affective dimensions, and to 'feed' into concrete outcomes such as intentions and even behaviours. Therefore, such a perspective is conceptually and empirically more informative than itemizing different dimensions of gratification or technology uses that are brand-related (e.g., Mutinga et al., 2011; Schivinski et al., 2016)

\section{The importance of consumer involvement}

Another conceptual assumption that characterises the present research concerns the need to consider one important driver of consumer engagement: consumer involvement. In the literature, consumer involvement has been defined as the inherent level of interest or personal relevance (see Mittal, 1995; Zaichkowsky, 1994). Brodie et al. (2011) highlight that involvement is a key antecedent of consumer engagement, and a number of studies have formally included consumer 
involvement as driver of consumer engagement - see Hollebeek (2011); Hollebeek et al., (2014); Vivek et al. (2012); and Dwivedi (2015). The relevance of involvement in the context of the consumer engagement can be understood quite well considering some of Bowden's (2009) reflections. Specifically, Bowden explained that involvement is somewhat 'stand-alone' in the engagement process and it matters because: i) it is an internal on-going psychological commitment, which corresponds to persistent and somewhat intense arousal, ii) it functions as the 'glue' connecting cognition, affect and behaviour, therefore playing a key role in the context of consumer decisions, and iii) it underpins positive responses to marketing initiatives and allows customer-brand relationships to 'stick'. Moreover, Fernandes and Proença (2008) argue that it is important to keep in mind that not all consumers are equally receptive to tactics aimed at engaging them, especially when faced with increased availability of offerings and/or low switching costs. That is, consumers will naturally have different levels of proneness to engagement, as resulting from the combination of contextual (e.g., complexity, switching costs etc.) and psychological factors such as involvement and expertise. This argument resonates greatly with the context of apps, where: i) consumer proneness to engaging with apps may be markedly impacted by the characteristics of the technology itself (e.g., Hennig-Thurau et al., 2010), and ii) there are many highly comparable offerings available at little or not cost.

In addition to the above argument, as with any other digital technology, it is reasonable to expect that the level of consumer involvement and expertise should play a crucial role in underpinning the resulting experience of apps consumption, ultimately triggering the engagement process. For example, Leckie, Nyadzayo and Johnson (2016) found that consumer involvement, participation, and self-expression are at the heart of consumer engagement with mobile service providers, positively impacting consumer loyalty. This finding is consistent with the work of 
Hollebeek et al. (2014) regarding consumer engagement in social media, and Wirtz et al.'s (2013) work on online communities.

In summary, combining all the conceptual insights and assumptions discussed so far, it is possible to formally outline the following overarching research proposition, which has informed and shaped the present research:

The perceptions of the benefits that a branded apps offers and how those benefits satisfy their individual needs result in a range of consumer experiences, which shape different types of motives (e.g., utilitarian and hedonic) for engaging with branded apps. These motives are underpinned by consumer involvement with branded apps in general, and incentivise specific outcomes of consumer engagement with a certain branded app. The next sections outline the methods used to outline a research framework for empirical testing on the basis of the above research proposition. 


\section{Study 1}

\section{Methods}

The first phase of this research involved a qualitative study consisting of five focus groups, each comprising of a purposive sample of current users of apps (Kuzel, 1992). The decision to use focus groups over other qualitative research techniques, such as in-depth interviews, is justified as follows. Compared to individual interviews, focus groups allow researchers to gather and compare individual views in a mock-up social setting, and observe and interpret group-level interactions (Morgan, 1996).

A call for research participants was emailed across the campus of a large UK university, offering an incentive (i.e., a gift voucher worth $£ 15$ ) to encourage participation. This resulted in a total sample of 22 participants (4-5 participants in each group), which included both students and staff. The students involved were from different cohorts (i.e., undergraduate and postgraduate, from different degrees) and the staff members participating had different roles within the university (e.g., some were professional staff members such as building maintenance staff, while others were academic staff from a varied number of different discipline), which mitigated the risk of a possible skew in the profile of the convenience sample - e.g., in relation to the education profile. There was an even split of students and staff members and the respondents' age ranged between 26 and 63, with an equal distribution of males and females. Each focus group lasted approximately one hour, and the discussions followed a semi-structured protocol. The questions included topics relating to consumers' thoughts about branded apps in regard to a variety of issues such as price, performance, convenience, usefulness, functionalities and, more generally, individual needs concerning apps. Group members were also asked about their current level of usage and their awareness of branded apps. The discussions were transcribed verbatim in 
anonymous format, and examined independently by three researchers following Spiggle's (1994) recommended steps for the interpretation and evaluation of qualitative data in consumer research.

All recurring themes identified following this approach were linked back to concepts and notions available in the literature, and aligned to specific aspects likely to motivate consumer to engage with branded apps. The key outcome of this study was a research model to be empirically tested in Study 2 (quantitative). The rationale for developing a model through a qualitative study of consumer perspectives and testing it quantitatively is justified as follows. First, Fernandes and Proença (2008) highlight that to fully understand consumer engagement it is fundamental to consider 'what the consumer wants' - i.e. what constitutes value for the consumer given that s/he will be directly involved in the co-creation of that value. The authors further remark that neglecting to consider consumers' perspectives could lead to a misunderstanding of engagement, given that consumers wish to engage with products and services in different ways and for different reasons. Second, Calder et al. (2016) recommend capturing consumer perceptions of the engagement context using qualitative research. Third, Larivière et al. (2013) suggest that embracing a consumer perspective to understand consumer engagement with media and technology is paramount. Additionally, Baldus, Voorhees and Calantone (2015) have used qualitative research to identify consumer motivations in the context of online communities' engagement; and Schivinski et al. (2016) used a combination of quantitative and qualitative methods to advance consumer engagement conceptualisation and measurement on the basis of Mutinga et al.'s (2011) assumptions.

\section{Results}

In relation to consumer involvement with branded apps, participants consistently indicated that they consider themselves involved with an app if: i) it matches their needs; ii) they use it all the 
time to the point of becoming really familiar with and preferring it to other apps; iii) the app performs as expected (i.e., it works properly and never 'crashes' on their device); or ii) if the app is highly recommended - see the following direct quote:

It's matching my needs, etc., and it works, so I'm like: why bother looking for something different? Unless somebody really, really totally recommends it. [Male, between 25 and 35 years old]

This outcome added to the assumptions outlined earlier in relation to the need to include consumer involvement as antecedent of consumer engagement in line with existing frameworks (e.g., Hollebeek 2011; Hollebeek et al., 2014; Vivek et al. 2012; Dwivedi, 2015); it also suggests the existence of a likely connection between consumer involvement with apps in general and the relevance of certain apps to particular individual needs. In fact, participants seemed to explicate their involvement in terms of frequent use and meeting (and even exceeding) expectations.

Accordingly, it seems plausible to assume the existence of a likely connection between involvement and the experiences that result from consumer perceptions of how a certain branded app meets individual needs, by means of offering certain benefits to a consumer.

\section{Utilitarian motives for engagement}

Among the utilitarian aspects discussed, participants recurrently and unanimously expressed concerns in regard to security and (personal) data protection. In particular, participants highlighted that often it is not clear how branded apps handle and protect their data, and pointed out that although consent may be sought, the information provided might not be sufficient. This is best exemplified by the following comments:

Whenever I have to download an app, I first just check the permissions, then I check who is the manufacturer/software producer, then I see what it does [...] because if it requires so 
many permissions I don't like it [...] there are a lot of apps that can steal your data; well, steal your identity, basically. [Male, between 25 and 35 years old]

Similarly, another participant commented:

I'm extremely concerned about security issues, about data protection. [...] I think we do not know enough about how these platforms are currently integrated and they are actually not informing people about data protection, etc. So, I'm totally against that. [Female, between 35 and 45 years old]

Interestingly, this finding seems consistent with conceptual models describing the drivers of acceptance and usage of mobile technologies (in general), which often refer to the notions of perceived risk (Wu \& Wang, 2005), permission-based acceptance (Gao, Rohm, Sultan, \& Pagani, 2013) and risk assurance (Chandra, Srivastava, \& Yin-Leng, 2010).

Participants then recurrently indicated different factors, which are likely to make them consider an app useful, as follows. First, they highlighted circumstances whereby a branded app can assist them with solving practical problems, such as handling an issue, transport, finding information, and performing tasks, e.g.:

I've got an app, which is a guitar tuner. So, basically, I don't have to carry a tuner around with me anymore [...] it just gives me one less thing to carry and it probably works better than the tuner [...] and it's more convenient to have it stored on here rather than as another thing to carry [Male, between 25 and 35 years old]

Second, participants also highlighted that branded apps become useful to them whenever they can reduce cognitive and behavioural efforts in relation to: i) remembering things, ii) organizing and managing tasks, iii) saving time, iv) making one's life easier, v) having a positive impact on 
specific aspects of one's life (e.g., health and lifestyle), and vi) allowing to separate private life and work life. For instance, one participant stated:

I guess it helps you to maintain a routine in your daily life [...] if there are apps there which kind of help you to keep track of things before you forget and then therefore become more organized. [Female, between 35 and 45 years old]

Third, participants also remarked that branded apps are useful in line with the extent to which they are workable and customizable:

Some apps don't need to be customised, like [those] sending facts or information. While the others, like [name of a productivity app] or, you know, email management apps, then yes, I do care about that. That's why I even downloaded the app, to personalise it. [Male, between 35 and 45 years old]

Fourth, participants associated usefulness of branded apps to the idea of convenience, availability and relevance to everyday matters, as exemplified by the following quotes:

I like to use apps just because they are fast and basically you can do that everywhere.

Many [...] like being online everywhere, every time, and updating their status everywhere.

[Female, between 25 and 35 years old]

I'd just choose it because it suits my needs and me. [Male, between 35 and 45 years old] Finally, participants pointed out that branded apps should be simple and easy to use (i.e., userfriendly, self-explanatory and easy to navigate). For instance, one person said:

Sometimes they're really badly designed. You see online app version of, say, online banking for example, where it's actually more difficult to access than it would have been if you'd just done it on a desktop. [Female, between 25 and 35 years old] 
Taken together, the findings concerning usefulness and ease of use of branded apps are indirectly consistent with Larivière et al.'s (2013) argument that consumers engage with media and technology to a greater extent when a certain medium or technology provides convenience, enabling consumers to complete tasks easily and quickly (including transactions) and/or to gather information. These outcomes are also consistent with literature describing the uptake and continuous use of apps in general (e.g., Tobjib \& Tsarenko, 2012; Yang, 2013; S. C. Kim et al., 2016). Lastly, these results are in line with Tarute et al.'s (2017) reflections concerning the importance of factors such as app functionality, design (or layout), interactivity and information quality as influencers of consumer engagement with apps.

\section{Hedonic motives for engagement}

Some recurring themes emerging from the discussions can be linked back to Papacharissi and Rubin's (2000) notion of interpersonal utility. That is, an individual's willingness and need for inclusion, affection, and control through the use of internet technologies - e.g., in relation to participating in discussion, belonging to a group, and self-expression. Specifically, participants highlighted that branded apps are crucial to satisfying their desire to share information and experiences with others, which assists them with self-expression, a sense of social belonging, and membership of specific 'groups' such as an extended family and friends. The following narratives exemplify these aspects:

I have at least like five or six applications, which [...] for me are very important because of talking to someone who's quite far and is not in the same country; it's very easy to do that without having to call and being charged [...] I cannot do without [messaging app name] because I have a daughter in Scotland and I like to speak to her every night. [Female, between 45 and 55 years old] 
I prefer to use an app because I have lots of friends there. So, it means it's a kind of necessity of having that app because it's much easier, cheaper and very comfortable [...] With things like [messaging app name] you can have group text messages, so if you're meeting up with people, it's a lot easier that than ringing everyone. [Female, between 25 and 35 years old]

It helps me to keep in touch with not only my friends, but also my colleagues as well [...] It helps me to keep in touch with people I love, even though they're not speaking. [Male, between 25 and 35 years old]

Participants also often remarked that they experienced high levels of attachment to the device powering the branded app, with connotations of addiction, as shown in the following quote: Even if you don't use it, you need your mobile next to you. It makes you feel safe. It's more about the physiological attachment. Addiction, that's the key word, I think. [Male, 45 to 55 years old].

This finding reflects how mobile technologies are often considered extensions of the selves and indispensable in daily life (E. Kim et al., 2013; Y.H. Kim et al., 2013). It is also akin to Sultan, Rohm and Gao's (2009) assumption that attachment with the device is one of the key drivers explaining consumer acceptance of mobile marketing tactics, rather than a factor that should be controlled for exogenously to the mechanisms considered.

Finally, perceptions in relation to entertainment and enjoyment were important for many participants. For example:

Apps are definitely for entertainment; I have some apps literally to just kind of pass a few minutes. If I'm, for example, outside waiting for someone, I'll pick my phone up and I'll play a silly game for five minutes [...] [Name of apps for music streaming] definitely 
classes as entertainment [...] so do fitness apps, apps for checking emails on the go, and social media apps. [Male, between 25 and 35 years old]

This finding is in accord with existing research, which identifies enjoyment as driver of usage of advanced mobile services, including apps (e.g., Tobjib \& Tsarenko, 2012). More importantly, the findings concerning hedonic motives are aligned with the work of Yang (2013), who binds entertainment and attachment in the specific context of mobile apps, and the work of Dessart et al. (2015), which includes enjoyment in the affective facet of consumer engagement.

\section{Likely outcomes}

Recurring themes emerging from the focus groups pointed to two likely outcomes of consumer engagement with branded apps, which imply interactions that extend beyond the app itself to other consumers. This finding that is consistent with the conceptualization of consumer engagement by Dessart et al. (2016) and research into online and mobile communication domains (e.g., Okazaki, 2008; 2009; Sun, Youn, Wu, \& Kuntaraporn, 2006).

The first outcome emerging from the discussions was the willingness to pay for a branded app and for in-app purchases such as upgrades to advert-free versions. Specifically, participants indicated that they would always pay for a branded app if demonstrably superior to comparable free alternatives, e.g.:

They always have like the live free version of a certain app that you can always try. Maybe I would go for the free first, but I would pay for it if I wasn't happy for what I could get for free [...] I find it very useful that you have this ability to try a bunch of free applications 
and then something meets your needs then you can either keep it as it is or buy the premium version. [Male, 25 to 35 years old]

The willingness to pay seems like a novel finding, since it is not a factor commonly highlighted in frameworks depicting the outcomes of consumer engagement. Arguably, a partial exception to this is Vivek et al.'s (2012) framework, which features the broad notion of value perception. Also, Stocchi et al. (2017) have recently highlighted that paid apps are often associated with perceptions of uniqueness and 'coolness', which seems in line with the finding emerging here.

A second recurring theme was the willingness to spread word-of-mouth or to recommend a branded app, such as rating and scoring it online to help the developers and other consumers. This theme is evident in the following comments:

I think you're unconsciously contributing towards the development of the app because these people in these companies will be collecting data on how you use it [...] so probably unconsciously we're all contributing. When I give feedback on an app, you know, whether it's online or on my mobile phone, I definitely think that I'm helping, at least assisting others. [Male, 45 to 55 years old]

Furthermore, word-of-mouth seemed to act as a key incentive to use a branded app, as demonstrated by the following quote:

I will read the customer reviews and how many customers have already the apps and they're rating the app. So, the better the review, the more I trust the app [...] I've downloaded apps quite a lot through word of mouth. [Male, 35 to 45 years old] Word-of-mouth recommendation has been included as outcome of consumer engagement in several studies, especially due to the facilitation offered by typical loci of engagement such as online communities (Brodie et al. 2011). Hennig-Thurau et al. (2004) articulated the motive of 
word-of-mouth in e-contexts, including its social nature in the form of concern for others. Calder et al. (2009) highlighted a series of second order manifestations of engagement, which included various forms of participation and social interaction. Similarly, Hoyer, Chandy, Dorotic, Krafft and Singh (2010) argued that consumer engagement underpins word-of-mouth referrals, whereas Roberts and Alpert (2010) and Vivek et al. (2012) included word-of-mouth as outcome of engagement in their frameworks. Also, Hollebeek and Chen (2014) highlighted word-of-mouth in e-contexts as one of the two key outcomes resulting from various facets of positive brand engagement, while Dessart et al. (2015) incorporated endorsement in the behavioural facet of engagement. Additionally, Jaakkola and Alexander (2014) analysed the outcomes of consumer engagement and, among other things, identify word-of-mouth as key manifestation of the value co-creation. Finally, Leckie et al. (2016) identify word-of-mouth as outcome of consumer engagement.

Resulting research framework for testing

Expanding on the general underlying conceptual assumptions about consumer engagement introduced earlier and taking into account the results of Study 1, Figure 1 illustrates the research framework for empirical testing in Study 2, comprising all individual items and conceptual pathways.

Figure 1. Framework for further testing 


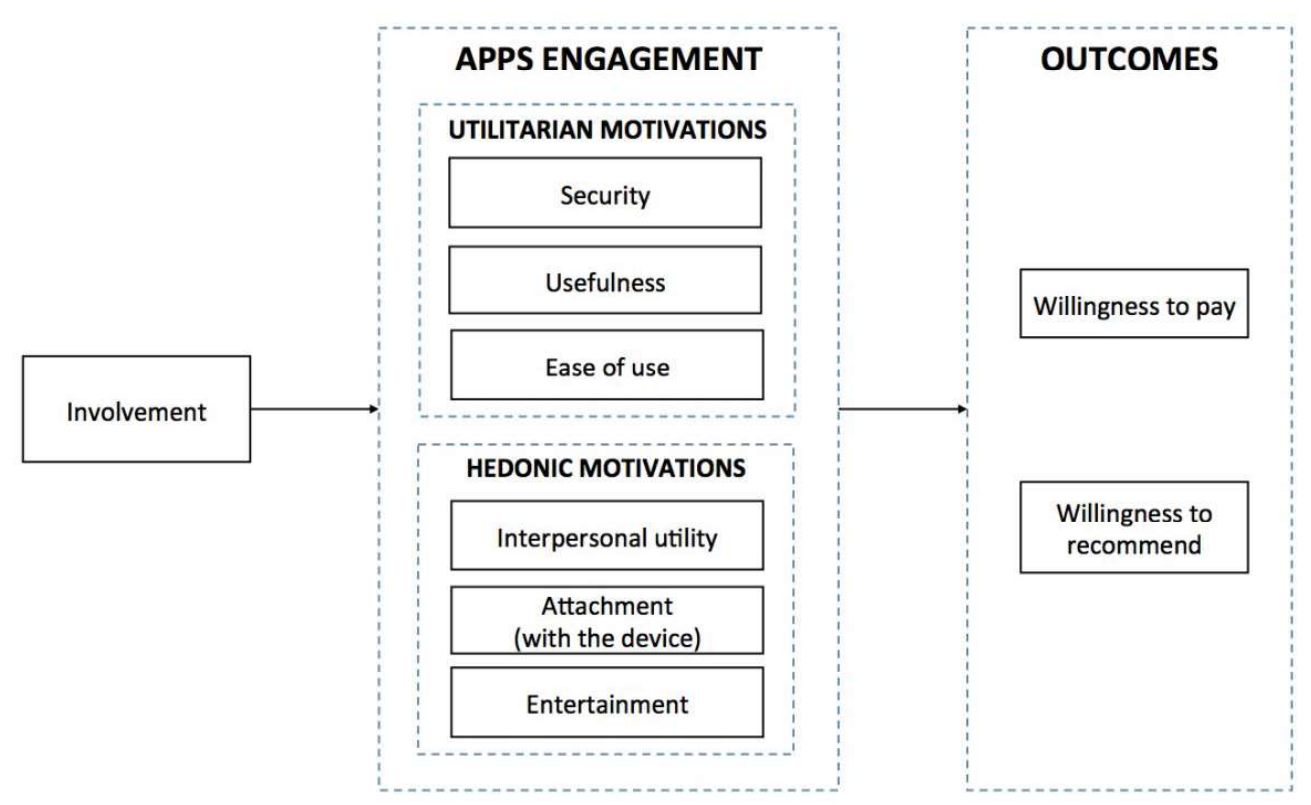




\section{Study 2 \\ Methods}

Data for this study were collected by means of an online questionnaire conducted by a UK panel data commercial provider. The provider has regular access to a very large population of UK consumers, whom they systematically contact via email with invitations to take part in online questionnaires such as the one included in this study. The protocol for the recruitment of participants and collection of responses that the provider uses follows recommended industry standards for quality assurance in market and consumer research. The participation is entirely voluntary and was administered independently by the commercial provider. The selection criteria for participation in this study were: i) UK consumer, 18 years old or above, and ii) owning and/or regularly using at least one device supporting apps.

In total, 335 responses were collected, out of which 253 were valid and usable, i.e. were complete and showed sufficient variations in the scores assigned to the questions included in the survey. This is an adequate sample size given the number of items included in PLS modelling (see Chin, 1998a). The sample consisted of 43.1 per cent males and 56.9 per cent females, with most answers coming from users aged between 18 to 33 years $(58.1 \%)$ and an equal distribution across income levels (see Table 1). This demographic profile is close enough to the overall population from which the sample was drawn, and it can therefore be considered a reasonable representation of UK consumers routinely using mobile technologies.

Respondents were presented with a list of 10 most-used branded apps in the UK at the time of this study (identified on the basis of AppAdvise.com, accessed on February 2015 - see Appendix A), including SNS apps, games and utilities (e.g., maps). The use of apps drawn from this list provided assurance of baseline familiarity and likely use of these branded apps by the 
targeted sample. Subsequently, respondents were asked to choose an app from the list and to answer a series of questions pertaining to that app (see Appendix A for the incidence of apps selection). Respondents were also offered the option to indicate a branded app of their choice if they did not feel like answering questions in relation to any of the apps from the list. This design allowed capture of a greater variance in responses while controlling for the individual app selected by respondents. More specifically, this analytical approach enabled the production of a more generalizable model with theoretical implications and is akin to the Bellman et al.'s (2011) and Tarute et al.'s (2017) approaches.

Table 1. Profile of respondents

\begin{tabular}{|c|c|c|}
\hline & $n$ & Percentage \% \\
\hline \multicolumn{3}{|l|}{ Gender } \\
\hline Male & 109 & 43.1 \\
\hline Female & 144 & 56.9 \\
\hline \multicolumn{3}{|l|}{ Age } \\
\hline $18-24$ & 17 & 6.7 \\
\hline $25-34$ & 55 & 21.7 \\
\hline $35-54$ & 147 & 58.1 \\
\hline $55+$ & 34 & 13.4 \\
\hline \multicolumn{3}{|l|}{ Income } \\
\hline Less than $£ 10,000$ & 52 & 20.6 \\
\hline$£ 10,000$ to $£ 19,999$ & 55 & 21.7 \\
\hline$£ 20,000$ to $£ 29,999$ & 46 & 18.2 \\
\hline$£ 30,000$ to $£ 39,999$ & 37 & 14.6 \\
\hline$£ 40,000$ to $£ 49,999$ & 21 & 8.3 \\
\hline$£ 50,000$ and more & 16 & 6.3 \\
\hline Prefer not to say & 26 & 10.3 \\
\hline
\end{tabular}

All questions and items included in the survey matched the findings of Study 1 and all measured items were presented using 1-5 Likert scales (strongly disagree to strongly agree). Table 2 provides more details of all measurement items, most of which were borrowed from existing research and adapted for the context of branded apps, as required.

Validation of the research model identified in Study 1 
In order to examine the conceptual pathways included in the framework identified in Study 1, Study 2 used a partial least square structural equation modelling (PLS-SEM) approach (Hair, Ringle \& Sarstedt, 2011) employing the SmartPLS (Ver. 2) path-analysis tool (Ringle et al., 2005). There are three reasons for using this approach. First, it is suitable for marketing studies, because it does not require the normality of employed constructs (Hair et al., 2012). Second, it can assist with theory development, while requiring less rigorous sample distribution assumptions (Hair et al., 2011). Third, compared to covariance-based SEM, it takes account of measurement errors (Chin, 1997; Hair et al., 2011).

Table 2 shows the results of the factor analysis for all significant latent constructs in the model. Factor loadings for the remaining items of all latent variables stood above the suggested value of 0.6 , with no major cross loading (nothing above 0.6 ). This confirms the convergent validity of the measurement items used.

Table 2. Details of all measurement items and factor loadings

\begin{tabular}{|c|c|c|}
\hline Details of the measures & Items & $\begin{array}{c}\text { Factor } \\
\text { loadings }\end{array}$ \\
\hline \multirow{6}{*}{$\begin{array}{l}\text { Involvement (adapted } \\
\text { from Michaelidou \& } \\
\text { Dibb, 2006) }\end{array}$} & INVL1 - It gives me pleasure to download and use mobile apps. & 0.7936 \\
\hline & $\begin{array}{l}\text { INVL2 - I can think of instances where a personal experience was affected by } \\
\text { the way I used mobile apps. }\end{array}$ & 0.6553 \\
\hline & $\begin{array}{l}\text { INVL3 - Because of my personal values, I feel that mobile apps ought to be } \\
\text { important to me. }\end{array}$ & 0.8405 \\
\hline & INVL4 - I enjoy downloading and using mobile apps. & 0.8376 \\
\hline & INVL5 - I rate my mobile apps as being of high importance to me. & 0.8587 \\
\hline & INVL6 - Mobile apps help me express who I am. & 0.8534 \\
\hline \multirow{2}{*}{$\begin{array}{l}\text { Security (adapted from } \\
\text { Miyazaki \& Fernandez, } \\
\text { 2001) }\end{array}$} & SECURE1 - My private information is managed securely when using this app. & 0.8783 \\
\hline & $\begin{array}{l}\text { SECURE2 - I am sure that payment information will be protected when using } \\
\text { this app. }\end{array}$ & 0.8787 \\
\hline \multirow{3}{*}{$\begin{array}{l}\text { Usefulness (adapted } \\
\text { from Davis, Bagozzi R. P., } \\
\text { \& Warshaw, 1989) }\end{array}$} & USEFUL1 - Using this app improves my performance in my daily life. & 0.9216 \\
\hline & USEFUL2 - Using this app increases my productivity in my daily life. & 0.9503 \\
\hline & USEFUL3 - Using this app enhances my effectiveness in my daily life. & 0.9552 \\
\hline \multirow{3}{*}{$\begin{array}{l}\text { Ease of use (adapted } \\
\text { from Davis et al., 1989) }\end{array}$} & EUSE1 - Learning to operate this app is easy for me. & 0.9026 \\
\hline & EUSE2 - I would find it easy to get this app to do what I want it to do. & 0.9442 \\
\hline & EUSE3 - It would be easy for me to become skilful at using this app. & 0.9508 \\
\hline \multirow{4}{*}{$\begin{array}{l}\text { Interpersonal utility } \\
\text { (from Papacharissi \& } \\
\text { Rubin, 2000) }\end{array}$} & IU1 - I use this app to help others. & 0.8235 \\
\hline & IU2 - I use this app to participate in discussions. & 0.8847 \\
\hline & IU3 - I use this app to show others encouragement. & 0.9128 \\
\hline & IU4 - I use this app to belong to a group. & 0.8757 \\
\hline
\end{tabular}




\begin{tabular}{lll}
\hline & IU5 - I use this app to express myself freely. & 0.8216 \\
\hline Attachment with the & ATTACH1 - I can't live without my smart phone and/or tablet. & 0.8886 \\
\cline { 2 - 3 } $\begin{array}{l}\text { device (from Gao et al. } \\
\text { 2013) }\end{array}$ & ATTACH2 - I use my mobile phone and/or tablet 24/7. & 0.8726 \\
\cline { 2 - 3 } $\begin{array}{ll}\text { Entertainment (from } \\
\text { Papacharissi \& Rubin, } \\
\text { 2000) }\end{array}$ & ENTACH3 - I am “addicted" to my mobile phone and/or tablet. & 0.9047 \\
\cline { 2 - 3 } & ENT2 - I use this app because it is entertaining. & 0.9233 \\
\cline { 2 - 3 } Willingness to pay & ENT3 - I use this app because I like it. & 0.9683 \\
\hline Willingness to & WILL2 - I am willing to pay a small fee for the app upgrades. & 0.9589 \\
\hline recommend & WOM1 - How likely are you to recommend this app to friends and family? & 0.9406 \\
\cline { 2 - 3 } & WOM2 - How likely are you to provide feedback on this app through online & 0.9461 \\
\hline
\end{tabular}

Cronbach's Alpha and composite reliabilities (see Table 3) returned values greater than 0.7 and 0.6, respectively (Hair et al., 2011), thus confirming the overall reliability of the measurement items. Furthermore, to appraise the total quality of the PLS model, this research included the assessment of redundancies and communalities (Tenenhaus, Vinzi, Chatelin \& Lauro, 2005). As Table 3 indicates, all redundancy indices were positive, thus confirming the quality of structural relations being examined (Hair et al., 2011).

In terms of the predictive power of the variables considered, all the $R^{2}$ values (see Table 3) exceeded the recommended cut-off value of 0.10 (Falk \& Miller, 1992). In more detail, involvement explains a moderate and significant proportion of the variance in utilitarian motives ( $R^{2}$ up to 0.29 for app usefulness) and of hedonic motives ( $R^{2}$ up to 0.38 for interpersonal utility). Similarly, it is evident that array of utilitarian and hedonic motives have moderate and significant explanatory power in relation to the variance in the willingness to pay for the app $\left(R^{2}=0.43\right)$ and the willingness to recommend the app $\left(R^{2}=0.28\right)$.

Table 3. Conceptual model measurement indices

\begin{tabular}{lccccc}
\hline & $\boldsymbol{R}^{\mathbf{2}}$ & $\begin{array}{c}\text { Composite } \\
\text { reliability }\end{array}$ & $\begin{array}{c}\text { Cronbach's } \\
\text { Alphas }\end{array}$ & Communality & Redundancy \\
\hline Involvement & & 0.9189 & 0.8929 & 0.6555 & \\
\hline Security & 0.1796 & 0.8712 & 0.7042 & 0.7717 & 0.1386 \\
\hline Usefulness & 0.2951 & 0.9598 & 0.9371 & 0.8883 & 0.2615 \\
\hline Ease of use & 0.1501 & 0.9525 & 0.9258 & 0.8700 & 0.0423 \\
\hline Interpersonal utility & 0.3822 & 0.9365 & 0.9149 & 0.7472 & 0.2842 \\
\hline Attachment (with the device) & 0.3327 & 0.9185 & 0.8673 & 0.7898 & 0.2608 \\
\hline
\end{tabular}




\begin{tabular}{llllll}
\hline Entertainment & 0.2347 & 0.9655 & 0.9463 & 0.9032 & 0.2114 \\
\hline Willingness to pay & 0.2781 & 0.9418 & 0.8764 & 0.8899 & 0.0843 \\
\hline Willingness to recommend & 0.4297 & 0.8863 & 0.7445 & 0.7958 & 0.0026 \\
\hline
\end{tabular}

In order to test for any possible Common Method Biases, this study used a full collinearity assessment approach (Kock, 2015), checking for the existence of vertical and lateral collinearity (Kock \& Gaskins, 2014; Kock \& Lynn, 2012), whereby any occurrence of a Variance Inflation Factor (VIF) greater than 3.3 is an indication of possible common method bias. All VIFs (at factor level) resulting from a full collinearity test were equal to or lower than 3.3 (see Table 4), except for involvement, where minor common method bias exists. This is a limitation that future research could attempt to overcome by selecting different indicators for measuring latent variables, latent variable aggregation and hierarchical analysis (see Kock \& Gaskins, 2014).

Table 4. Common Method Variance test

\begin{tabular}{lccccccccc}
\hline & \multicolumn{10}{c}{ Inner VIF values } \\
\cline { 2 - 12 } & $\mathbf{1}$ & $\mathbf{2}$ & $\mathbf{3}$ & $\mathbf{4}$ & $\mathbf{5}$ & 6 & 7 & 8 & 9 \\
\hline 1- Involvement & - & 3.519 & 3.402 & 3.611 & 2.619 & 2.864 & 3.622 & 3.626 & 3.624 \\
\hline 2- Security & 2.016 & - & 1.832 & 2.082 & 2.073 & 2.002 & 1.882 & 2.077 & 2.061 \\
\hline 3- Usefulness & 2.031 & 1.909 & - & 2.082 & 2.167 & 2.161 & 2.043 & 2.04 & 2.146 \\
\hline 4- Ease of Use & 1.676 & 1.686 & 1.619 & - & 1.675 & 1.682 & 1.583 & 1.664 & 1.485 \\
\hline 5- Interpersonal Utility & 1.407 & 1.945 & 1.951 & 1.94 & - & 1.909 & 1.939 & 1.944 & 1.936 \\
\hline 6- Attachment (with device) & 1.577 & 1.924 & 1.994 & 1.996 & 1.956 & - & 1.824 & 1.954 & 1.997 \\
\hline 7- Entertainment & 2.454 & 2.227 & 2.319 & 2.312 & 2.445 & 2.244 & - & 2.458 & 2.177 \\
\hline 8- Willingness to pay & 1.543 & 1.543 & 1.454 & 1.526 & 1.539 & 1.51 & 1.543 & - & 1.506 \\
\hline 9- Willingness to recommend & 2.449 & 2.431 & 2.429 & 2.162 & 2.433 & 2.45 & 2.171 & 2.391 & - \\
\hline
\end{tabular}

In order to demonstrate the global quality of the structural PLS modelling (Tenenhaus et al., 2005), this study used a blindfold approach (Chin, 1998b). Q squared values for all constructs are positive (Tenenhaus et al., 2005), and yield significant predictive relevance. Finally, in relation to discriminant validity (see Table 5), all the AVE values were above the minimum acceptable value of 0.5 (Fornell \& Larcker, 1981) and exceeded the squared inter-construct correlations, indicating the distinctiveness of all constructs (see Hair et al., 2011). 
Table 5. Latent variable correlations and discriminant validity

\begin{tabular}{lllllllllll}
\hline & AVE & \multicolumn{10}{c}{ Squared Correlations } \\
\cline { 3 - 11 } & & 1 & 2 & 3 & 4 & 5 & 6 & 7 & 8 & 9 \\
\hline 1. Involvement & 0.65 & - & & & & & & & & \\
\hline 2. Security & 0.77 & 0.18 & - & & & & & & \\
\hline 3. Usefulness & 0.88 & 0.29 & 0.22 & - & & & & & \\
\hline 4. Ease of use & 0.87 & 0.05 & 0.10 & 0.11 & - & & & & \\
\hline 5. Interpersonal utility & 0.74 & 0.38 & 0.08 & 0.12 & 0.01 & - & & & \\
\hline 6. Attachment (with the & 0.78 & 0.33 & 0.05 & 0.12 & 0.02 & 0.11 & - & & \\
\hline 7. Entertainment & 0.90 & 0.23 & 0.20 & 0.10 & 0.22 & 0.13 & 0.19 & - & \\
\hline 8. Willingness to pay & 0.88 & 0.19 & 0.09 & 0.21 & 0.02 & 0.11 & 0.12 & 0.07 & - \\
\hline 9. Willingness to & 0.79 & 0.17 & 0.15 & 0.16 & 0.23 & 0.11 & 0.09 & 0.30 & 0.10 & - \\
\hline
\end{tabular}

\section{Analysis of the conceptual relationships}

To test all conceptual relationships via estimating the path coefficients and statistical significance (T-statistics), this study used a bootstrapping method (Hulland, 1999). Overall, 5,000 resamples were generated from the 253 cases and they replaced the original data set for each parameter in the model (Chin, 1998a; Hair et al., 2011). Table 6 exhibits the results of the PLS path analysis. Comprehensively, consumer involvement significantly and positively influences the utilitarian and hedonic motives resulting from consumer perceptions of the benefits that the branded apps they chose to comment on offers to them, and the resulting experiences that such perceptions shape. This outcome sheds light on a number of important mechanisms according to which consumers can be motivated to engage with apps, and leading to two key outcomes, as follows.

Table 6. Results of PLS path analysis

\begin{tabular}{lllll}
\hline Paths & $\begin{array}{l}\text { Paths } \\
\text { coeff. }\end{array}$ & $\begin{array}{l}\text { Standard } \\
\text { deviation }\end{array}$ & T statistics & \\
\hline Involvement $\rightarrow$ Security & 0.4237 & 0.0474 & $8.9317^{* *}$ & Supported \\
\hline Involvement $\rightarrow$ Usefulness & 0.5432 & 0.0398 & $13.6545^{* *}$ & Supported \\
\hline Involvement $\rightarrow$ Ease of use & 0.2239 & 0.0450 & $4.9718^{* *}$ & Supported \\
\hline Involvement $\rightarrow$ Interpersonal utility & 0.6182 & 0.0364 & $16.9868^{* *}$ & Supported \\
\hline Involvement $\rightarrow$ Attachment (with the device) & 0.5768 & 0.0313 & $18.4457^{* *}$ & Supported \\
\hline Involvement $\rightarrow$ Entertainment & 0.4844 & 0.0379 & $12.7665^{* *}$ & Supported \\
\hline
\end{tabular}




\begin{tabular}{lllll}
\hline Security $\rightarrow$ Willingness to pay & 0.0651 & 0.0448 & 1.4525 & Not Supported \\
\hline Security $\rightarrow$ Willingness to recommend & 0.0761 & 0.0462 & $1.6487^{*}$ & Supported \\
\hline Usefulness $\rightarrow$ Willingness to pay & 0.3234 & 0.0500 & $6.4626^{* *}$ & Supported \\
\hline Usefulness $\rightarrow$ Willingness to recommend & 0.1485 & 0.0445 & $3.3366^{* *}$ & Supported \\
\hline Ease of use $\rightarrow$ Willingness to pay & 0.0536 & 0.0490 & 1.0956 & Not Supported \\
\hline Ease of use $\rightarrow$ Willingness to recommend & 0.2415 & 0.0465 & $5.1891^{* *}$ & Supported \\
\hline Interpersonal utility $\rightarrow$ Willingness to pay & 0.1335 & 0.0463 & $2.8822^{* *}$ & Supported \\
\hline Interpersonal utility $\rightarrow$ Willingness to & 0.1097 & 0.0406 & $2.7012^{* *}$ & Supported \\
\hline Attachment (with the device) $\rightarrow$ Willingness to & 0.1744 & 0.0495 & $3.521^{* *}$ & Supported \\
\hline Attachment (with the device) $\rightarrow$ Willingness to & 0.0132 & 0.0377 & 0.3508 & Not Supported \\
\hline Entertainment $\rightarrow$ Willingness to pay & 0.3122 & 0.0520 & $5.9992^{* *}$ & Supported \\
\hline Entertainment $\rightarrow$ Willingness to recommend & 0.0405 & 0.0555 & 0.7297 & Not Supported \\
\hline Willingness to pay $\rightarrow$ Willingness to recommend & 0.1071 & 0.0392 & $2.7333^{* *}$ & Supported
\end{tabular}

** $p<0.01, * p<0.05$ (one-tailed)

First, consumer involvement has a positive and significant impact on security $(\beta=04237, t=$ $8.9317)$, ease of use $(\beta=0.2239, t=4.9718)$ and usefulness $(\beta=0.5432, t=13.6545)$. Consumer involvement also has a positive and significant impact on interpersonal utility $(\beta=0.6182, t=$ 16.9868), attachment with the device powering the app $(\beta=0.5768, t=18.4457)$ and entertainment $(\beta=0.4844, t=12.7665)$. Second, all utilitarian motives returned a positive underlying effect with at least one of the two key outcomes considered. In more detail, security and ease of use both underpin the willingness to recommend the app $(\beta=0.0761, t=1.6487$; and $\beta=0.2415, t=5.1891$, respectively); usefulness underpins the willingness to pay for the app (including for in app features) $(\beta=0.3234, t=6.4626)$ as well as the willingness to recommend the app $(\beta=0.1485, t=3.3366)$. Similarly, all hedonic motives also show a positive effect on at least one of the two outcomes. That is, attachment with the device powering the app and entertainment drive the willingness to pay for the app $(\beta=0.1744, t=3.521$; and $\beta=0.3122, t=$ 5.9992, respectively); interpersonal utility drives the willingness to pay for the app $(\beta=0.1335, t$ $=2.8822)$ and the willingness to recommend the apps $(\beta=0.1097, t=2.7012)$. Last, the empirical analysis revealed that willingness to pay underpins with willingness to recommend an app $(\beta=0.1071, t=2.733)$. This was not detected or anticipated in Study 1 result, but it is an 
outcome of the empirical analysis that is worth highlighting, since it suggests that consumers who are willing to pay for a branded app or its features might also want to share their perception of the app with other consumers and talk about it, e.g. in the context of online reviews.

These confirm that, depending on the overall level of involvement with branded apps in general, the extent to which consumers perceive that an app safeguards their privacy and enables heightened security of their information (e.g., addresses, location, credit card information, etc.), together with the usefulness of the app and its ease of use will provide them with utilitarian motivation to engage with the app. Consumer involvement with branded apps also underpins hedonic motives resulting from: i) consumer perceptions concerning the interpersonal utility of the app (ability to self-express), ii) the overall sense of attachment to the device powering the app, and iii) how entertaining the app is. Importantly, all these links are relative to a consumer's perceptions of how the benefits that a certain branded app offers meet their individual needs (i.e., in relation to all these aspects), as they personally experience them. These mechanisms are fundamental because, combined, the array of utilitarian and hedonic motives that emerge drive two key outcomes: the willingness to pay for the app and the willingness to spread word-ofmouth recommendation. These are novel empirical findings, which extend the line of work of several studies on branded apps, such as Y.H. Kim et al. (2013), Viswanathan et al., (2017) and Tarute et al., (2017). Figure 2 presents visually the resulting validated framework.

Figure 2. Validated framework 


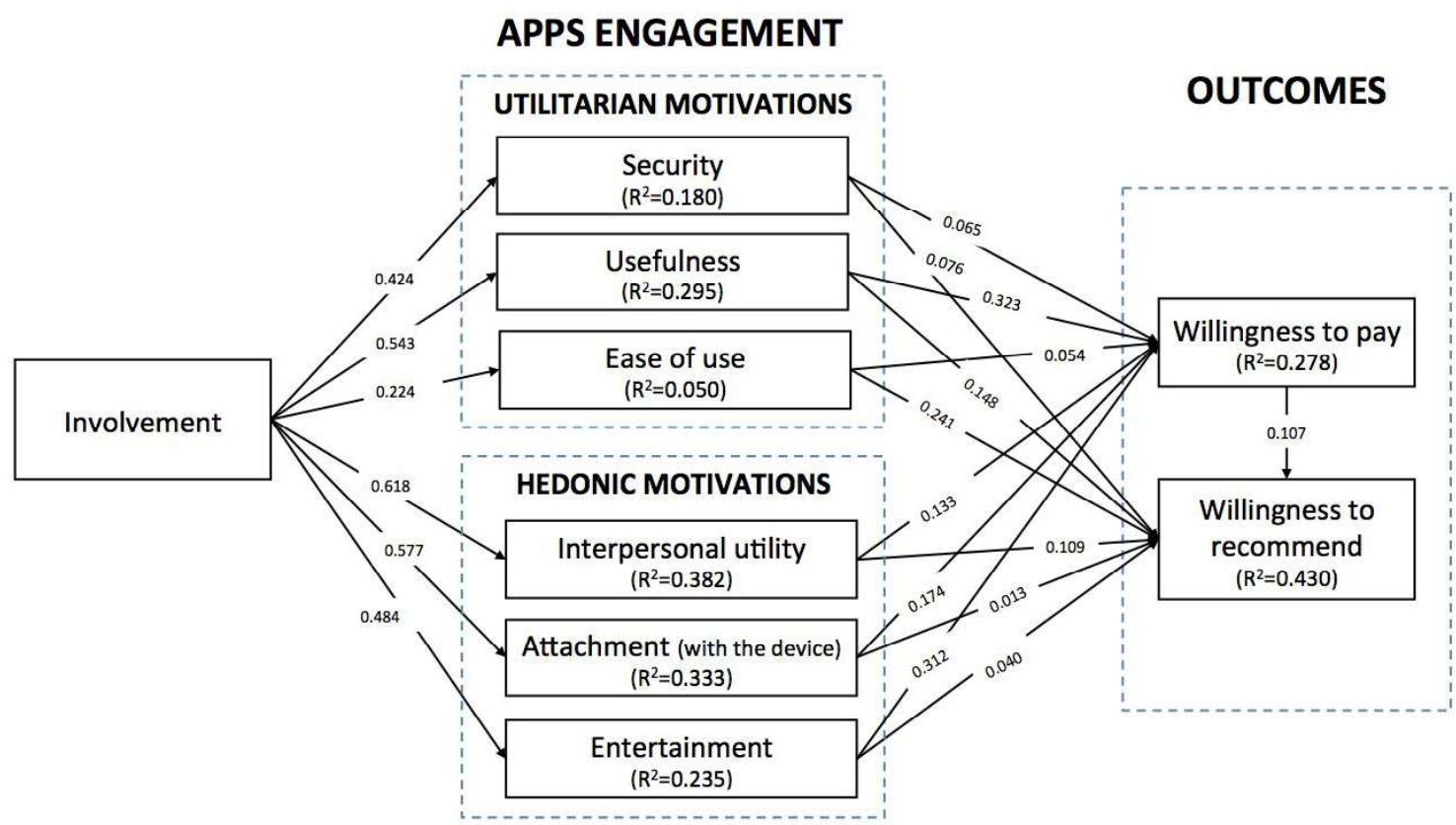

For completion, this study also included some mediation tests to evaluate the likely indirect effects. Table 7 reveals the mediating effects of both utilitarian and hedonic motives. Out of the hedonic motivations, entertainment mediates the relationship between involvement with branded apps and the willingness to recommend a certain branded app (indirect effect $=0.181 ; p$-value $=$ 0.004), whereas attachment with the device mediates the relationship between involvement with branded apps and the willingness to pay for a certain branded app (indirect effect $=0.069$; value $=0.029)$. Among the utilitarian motives, ease of use mediates the relationship between involvement with branded apps in general and the willingness to recommend a certain branded app (indirect effect $=0.181 ; p$-value $=0.004)$, whereas usefulness mediates the relationship between involvement with branded apps and the willingness to pay for a specific branded app (indirect effect $=0.200 ; p$-value $=0.003$ ).

Table 7. Results of mediation analysis

\begin{tabular}{lcccc}
\hline & $\begin{array}{c}\text { Indirect } \\
\text { Paths }\end{array}$ & $\begin{array}{c}\text { T } \\
\text { Effects }\end{array}$ & $\begin{array}{c}\text { Statistics } \\
\text { Values }\end{array}$ & \\
\hline Involvement $->$ Attachment $->$ WOM & -0.016 & 0.31 & 0.756 & Not sig \\
\hline
\end{tabular}




\begin{tabular}{|c|c|c|c|c|}
\hline Involvement -> Entertainment -> WOM & 0.181 & 2.891 & 0.004 & Significant \\
\hline Involvement $->$ Ease of Use $->$ WOM & 0.069 & 2.189 & 0.029 & Significant \\
\hline Involvement -> Interpersonal Utility -> WOM & 0.076 & 1.389 & 0.165 & Not sig \\
\hline Involvement -> Security -> WOM & 0.054 & 0.705 & 0.481 & Not sig \\
\hline Involvement -> Usefulness -> WOM & 0.067 & 1.089 & 0.276 & Not sig \\
\hline Involvement -> Attachment -> Willingness To pay & 0.132 & 2.164 & 0.03 & Significant \\
\hline Involvement -> Entertainment -> Willingness To pay & 0.009 & 0.147 & 0.883 & Not sig \\
\hline Involvement -> Ease of Use -> Willingness To pay & -0.017 & 0.754 & 0.451 & Not sig \\
\hline Involvement -> Interpersonal Utility -> Willingness To pay & 0.093 & 1.714 & 0.087 & Not sig \\
\hline Involvement -> Security -> Willingness To pay & 0.049 & 0.704 & 0.481 & Not sig \\
\hline Involvement -> Usefulness -> Willingness To pay & 0.2 & 2.994 & 0.003 & Significant \\
\hline
\end{tabular}

\section{Discussion}

Across two complementary studies (Study 1 and Study 2) this research has introduced and validated a framework to explain how consumers become motivated to engage with apps. The framework emerged from key underlying conceptual assumptions drawn from research that has explored consumer engagement in the context of mobile technologies (e.g., Y.H. Kim et al., 2013) and more specifically mobile apps (e.g., Viswanathan et al., 2017; Tarute et al., 2017). However, unlike existing works, the present research has focused on a theorisation of consumer engagement with branded apps that is akin to earlier studies that theorised engagement as a psychological (motivational) state. As such, this research has explored the tantalising possibility of consumer engagement with branded apps being likely to originate from the perceptions of the utilitarian and hedonic benefits that branded apps deliver, and the experiences that consumers have in relation to how the app satisfies their individual needs (see also Calder et al., 2016; Malthouse et al., 2016). Those perceptions (and resulting experiences) motivate consumers to engage with branded apps and lead to a couple of noteworthy outcomes. As such, conceptually and analytically, this research also draws upon earlier works on media engagement (Calder \& Malthouse, 2008; Calder et al., 2009; Davis Mersey et al., 2010). Furthermore, unlike existing research the present work has focused on generating predictions in relation to the app itself, thus 
extending the scope of the empirical findings to the management of apps that are inherently branded as extensions of existing brands as well as independent digital offerings. Therefore, this research offers some relevant insights that have theoretical as well as practical implications, as follows.

\section{Theoretical implications}

Taken together, the outcomes of Study 1 and Study 2 revealed that consumer involvement underpins a series of utilitarian and hedonic motivations resulting from consumer perceptions of the benefits that a branded app, and how consumers feel (or experience) that those benefits satisfy their personal needs. In more detail, consumers might become motivated to engage with branded apps because they experience that the app meets their needs in relation to protecting their personal data, or usefulness in their lives, and in relation to ease of use (utilitarian motives). That is, consumers might be encouraged to engage with a branded app if the app assists them with practical problems and reducing efforts, meeting their needs especially through customisation and seamless availability. Consumers might also become motivated to engage with a branded app if they experience that it can meet their needs to connect with others and self-express. This goes hand in hand with two other hedonic motives: the experience resulting from the substantial attachment towards the device powering the app and the entertainment aspect, both of which further heighten the motivation to engage with a branded app. Besides being motives that underpin engagement, the same aspects also lead to two key outcomes. A key unexpected outcome is the willingness to pay for a branded app (including in-app purchases), whereas a rather expected outcome is the willingness to recommend the branded app - a finding that is akin to other contexts of consumer engagement (e.g., social media and online communities). 
Thus, the main contribution of this work lies within the literature concerning branded apps and, more generally, mobile apps, due to the following reasons. Existing works have mainly focused on examining post-adoption outcomes, including engagement, but often from the perspective of mobile technologies as a whole (rather than specific instances of individual apps) or focusing on predictions for the brand powering the app. As discussed, existing research on post-adoption has also returned contrasting conceptualisations of consumer engagement with apps, and limited empirical scope. In contrast, this research draws upon relevant consumer engagement literature (especially with media) and revealed empirically how to motivate consumers to engage with branded apps.

Finally, Hollebeek, Conduit and Brodie (2016) have recently remarked that consumer engagement has rapidly developed as a field of research; yet, additional conceptual and empirical advancements are needed to validate its strategic relevance across contexts, especially mobile technologies such as apps. Therefore, in this regard, the present research also indirectly contributes to literature on consumer engagement, which thus far has been focused primarily on exploring online communities and social media.

\section{Practical (managerial) implications}

Expanding upon relationship marketing and S-D logic, it is widely accepted that consumer engagement can lead to positive outcomes such as customer retention, word-of-mouth, loyalty and value co-creation (Brodie et al. 2011). As such, consumer engagement can enhance market performance and lead to the attainment of a competitive advantage (see also Bowden, 2009; Schau, Muñiz, \& Arnould, 2009; Gambetti \& Graffigna, 2010; Chan \& Li, 2010; Brodie et al. 2011; Hollebeek, 2011). Indeed, as E. Kim et al. (2013) stated, successful technologies do not merely attract users; they engage them, triggering a process whereby different types of 
motivation (e.g., utilitarian and hedonistic) work 'in sync', driving value creation and satisfaction. Interestingly, E. Kim et al. (2013) put forward some untested assumptions on the possibility of successfully engaging consumers with apps, thereby positively impacting market performance, which the present study has broadly confirmed. Namely, Kim et al. argued that specific characteristics of branded apps (i.e., vividness, novelty, motivation, control, customization, feedback and multi-platform) could make apps more engaging than web-based technologies. The two complementary empirical studies in the present research shed much more light on these aspects and complemented conceptual assumptions concerning how consumer engagement with branded apps is supposed to work. Accordingly, it is possible to translate the outcomes of this research into a series of practical insights with managerial relevance, as follows.

First and foremost, it seems crucial that the providers of branded apps should take into consideration the fundamental role that the general level of consumer involvement with apps plays as driver of consumer perceptions of the benefits that an app offers and of how those benefits meet their individual needs. The experiences resulting from these aspects seem to be clearly aligned with a series of specific utilitarian and hedonic motives for engaging with the apps. Accordingly, providers of branded apps should focus, in the first place, on designing strategies to generate interest in branded apps and involve consumers. Second, providers of branded apps should bolster and communicate the benefits that an app offers in relation to practical aspects that can act as stimuli to utilitarian motives, i.e. security, ease of use and usefulness of the app. An example of how this could be achieved is represented by the Facebook in-app communication strategy concerning security and privacy features (see Figure 4). At the same time, hedonic aspects should not be neglected. That is, branded apps should be designed and marketed in a way that clearly conveys benefits for self-expression and connection with other 
consumers (i.e., interpersonal utility) and entertainment possibilities, while taking into account the attachment between the consumer and the device powering the app. For instance, branded apps such as food delivery apps or any other apps that facilitate the provision of immediate rewards and enjoyment for consumers should communicate this clearly and emphasise this aspect (see Figure 3). These factors, combined, provide consumers with positive perceptions of how the benefits that the app offers meet their individual needs and experiencing this motivates consumers to engage with a branded app, ultimately leading to outcomes with clear economic benefits such as paying for the app and/or making in-app purchases, and word-of-mouth recommendation.

Figure 3. Examples of strategies to communicate utilitarian and hedonic benefits of apps

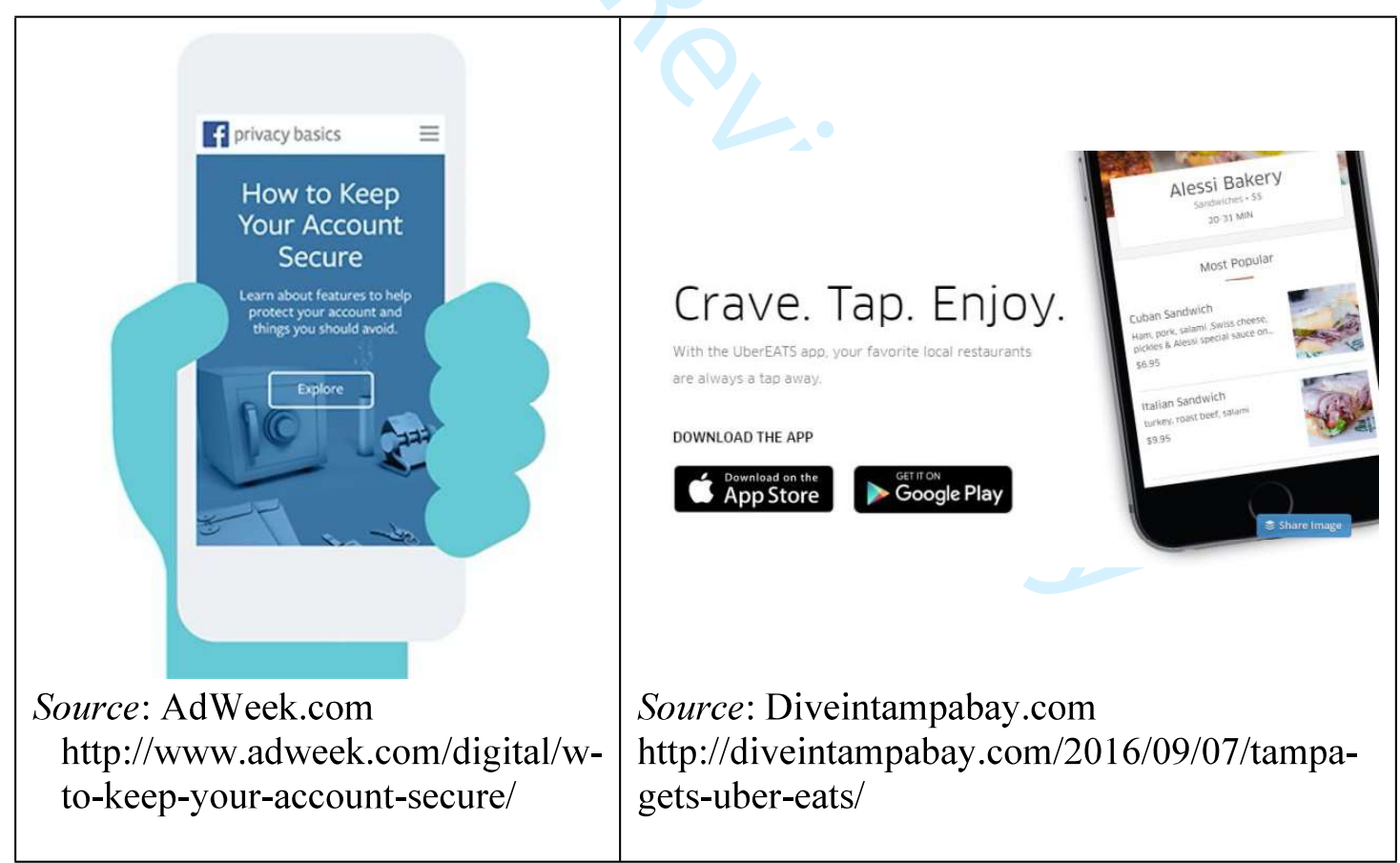

In addition to the above, the outcomes of this research suggest that certain features of branded apps are more readily associated with utilitarian motives, while others are more readily linked to 
hedonic motives. Put simply, providers of branded apps could encourage consumers to engage with an app by bolstering utilitarian factors, e.g. by: i) heightening its level of security in relation to sensitive data protection and retention policies, ii) making the app easy to use by improving and streamlining its functionality and layout, and iii) ensuring that the app is useful by enhancing its convenience, customization, and fit with people's lives. Similarly, providers of branded apps could also influence consumers' motivation to engage with the app by leveraging hedonic aspects, e.g. by i) ensuring that the apps facilitate self-expression and a sense of belonging and connection with other consumers, ii) being mindful of consumer attachment with the device powering the apps (for instance, making the app highly compatible with such devices), and iii) making the app as entertaining as possible.

\section{Conclusions, limitations and future research directions}

This study revealed that consumer involvement with branded apps in general feeds into consumer perceptions of the benefits that apps offer, shaping a range of experiences that motivate the consumer to engage with branded apps. These perceptions emerge from satisfying individual consumer needs and underpin a range of utilitarian and hedonic motivations, which then lead to two relevant outcomes. Namely, they entice the consumer to spread word-of-mouth recommendation, and to a willingness to pay for a branded app or to make in-app purchases. Accordingly, the present research contributes to advancing knowledge about branded apps beyond describing standard post-uptake matters (focus of most existing empirical works). The present research also explains the psychological (motivational) state that lies at the heart of consumer engagement with branded apps. Hence, the most relevant practical implication of this work resides in the revelation that by improving consumer involvement with branded apps in 
general, it is possible to enhance perceptions of the benefits that apps offer and to motivate consumers to engage with a specific branded app. This will ultimately influence outcomes with clear economic returns such as word-of-mouth recommendations and willingness to pay for a branded app.

Nonetheless, as with any research, the present work is not without limitations, some of which require replications and future research. Above all, it will be essential to explore a broader spectrum of consumer perceptions of the benefits of branded apps and to examine additional facets of the different types of motives embedded in the process of motivating consumers to engage with branded apps. Furthermore, a natural advancement of this work should be to expand the framework to other behavioural outcomes such as app loyalty, taking into account relevant moderating factors such as frequency of use, number of apps used and different types of branded apps. The last aspect mentioned here (i.e., comparison by types of branded apps) is particularly relevant, because one could expect different types of branded apps to 'tap' more into utilitarian or hedonic motives (e.g., an app for email access, such as the Outlook app, vs. an app for accessing movies and TV shows 'on the go', such as the Netflix app). The data used in Study 2 did not allow for such a comparison, but future research should explore this aspect in detail. Last, the present work is based on data from one country in which the penetration and familiarity of branded apps are very high, which could have underpinned the relevance of consumer involvement in the identified framework; thus, future research should consider contexts where the uptake of branded apps is lower. 


\section{References}

Abdul-Ghani, E., Hyde, K. F., \& Marshall, R. (2012). Consumer engagement or customer engagement? Two competing views on a phenomenon. ACR Asia-Pacific Advances.

Alnawas, I., \& Aburub, F. (2016). The effect of benefits generated from interacting with branded mobile apps on consumer satisfaction and purchase intentions. Journal of Retailing and Consumer Services, 31, 313-322.

Baldus, B. J., Voorhees, C., \& Calantone, R. (2015). Online brand community engagement: Scale development and validation. Journal of Business Research, 68(5), 978-985.

Bellman, S., Potter R. F., Treleaven-Hassard S., Robinson J. A., \& Varan D. (2011). The effectiveness of branded mobile phone apps. Journal of Interactive Marketing, 25(4), 191 200.

Bowden J. L. H. (2009). Customer engagement: A framework for assessing customer-brand relationships: the case of the restaurant industry. Journal of Hospitality Marketing and Management, 18(6), 574-96.

Brodie, R. J., Ilic A., Juric B., \& Hollebeek L. (2011). Consumer engagement in a virtual brand community: An exploratory analysis. Journal of Business Research, 66(1), 105-114.

Calder, B. J., Isaac M. S., \& Malthouse E. C. (2016). How to capture consumer experiences: A context-specific approach to measuring engagement. Journal of Advertising Research, 56(1) 39-52,

Calder, B. J., \& Malthouse, E. C. (2004). Qualitative media measures: Newspaper experiences. International Journal on Media Management, 6(1-2), 123-130.

Calder, B. J., \& Malthouse, E. C. (2008). Media engagement and advertising effectiveness. Kellogg on advertising and media, 1-36.

Calder, B. J., Malthouse, E. C., \& Schaedel, U. (2009). An experimental study of the relationship between online engagement and advertising effectiveness. Journal of Interactive Marketing, 23(4), 321-331.

Chan, K., \& Li S. Y. (2010). Understanding consumer-to-consumer interactions in virtual communities: The salience of reciprocity. Journal of Business Research, 63(9), 10331040. 
Chandra, S., Srivastava, S. C., \& Yin-Leng, T. (2010). Evaluating the role of trust in consumer adoption on mobile payment systems: An empirical analysis. Communications of the Association for Information Systems, 27(1), 561-588.

Chen, L., Meservy, T. O., \& Gillenson, M. (2012). Understanding Information Systems Continuance for Information-Oriented Mobile Applications. Communications of the Association for Information Systems, 30(1),127-146.

Chin, W. W. (1997). Overview of the PLS method. University of Houston. Retrieved from http://disc-nt.cba.uh.edu/chin/PLSINTRO.HTM

Chin, W. W. (1998a). Commentary: Issues and opinion on structural equation modeling. Management Information Systems Research Center, University of Minnesota https://www.jstor.org/stable/249674

Chin, W. W. (1998b). The partial least squares approach to structural equation modeling. In G. A. Marcoulides (Ed.), Methodology for business and management. Modern methods for business research (pp. 295-336). Mahwah, NJ, US: Lawrence Erlbaum Associates Publishers.

Choi, H., Kim, Y., \& Kim, J. (2011). Driving factors of post adoption behavior in mobile data services. Journal of Business Research, 64(11), 1212-1217.

Davis, F. D., Bagozzi R. P., \& Warshaw P.R. (1989). User acceptance of computer technology: A comparison of two theoretical models. Management Science, 35(8), 982-1003.

Davis Mersey, R., Malthouse, E. C., \& Calder, B. J. (2010). Engagement with online media. Journal of Media Business Studies, 7(2), 39-56.

Dessart, L., Veloutsou, C., \& Morgan-Thomas, A. (2015). Consumer engagement in online brand communities: A social media perspective. Journal of Product \& Brand Management, 24(1), 28-42.

Dessart, L., Veloutsou, C., \& Morgan-Thomas, A. (2016). Capturing consumer engagement: Duality, dimensionality and measurement. Journal of Marketing Management, 32(5-6), $399-426$.

Dovaliene, A., Piligrimiene, Z., \& Masiulyte, A. (2016). Factors influencing customer engagement in mobile applications. Engineering Economics, 27(2), 205-212. 
Dwivedi, A. (2015). A higher-order model of consumer brand engagement and its impact on loyalty intentions. Journal of Retailing and Consumer Services, 24(Supplement C), 100109.

Falk, R. F., \& Miller N. B. (1992). A primer for soft modeling (1st ed.). Akron, OH: University of Akron Press.

Fang, Y. H. (2017). Beyond the Usefulness of Branded Applications: Insights from ConsumerBrand Engagement and Self-construal Perspectives. Psychology \& Marketing, 34 (1), 4058.

Fernandes, T. M., \& Proença J. F. (2008). The blind spot of relationships in consumer markets: The consumer proneness to engage in relationships. Journal of Marketing Management, 24(1-2), 153-168.

Fornell, C, \& Larcker D. F. (1981). Evaluating structural equation models with unobservable variables and measurement error. Journal of Marketing Research, 18(1), 39-50.

Furner, C.P., Racherla, P. \& Babb, J.S. (2014). Mobile app stickiness (MASS) and mobile interactivity: a conceptual model. The Marketing Review, 14 (2), 163-88.

Gambetti, R., \& Graffigna G. (2010). The concept of engagement. International Journal of Market Research, 52(6), 801-826.

Gao, T. T., Rohm A. J., Sultan F., \& Pagani M. (2013). Consumers un-tethered: A three-market empirical study of consumers' mobile marketing acceptance. Journal of Business Research, 66(12), 2536-2544.

Hair, J. F., Ringle C. M., \& Sarstedt M. (2011). PLS-SEM: Indeed a silver bullet. Journal of Marketing Theory and Practice”, 19(2), 139-152.

Hair, J. F., Sarstedt M., Ringle C. M., \& Mena J. A., (2012). An assessment of the use of partial least squares structural equation modeling in marketing research. Journal of the Academy of Marketing Science, 40(3), 414-433.

Hennig-Thurau, T., Malthouse E. C., Friege C., Gensler S., Lobschat L., Rangaswamy A., \& Skiera B. (2010). The impact of new media on customer relationships. Journal of Service Research, 13(3), 311-330.

Ho, S. Y. (2012). The effects of location personalization on individuals' intention to use mobile services. Decision Support Systems, 53(4), 802-812. 
Hollebeek, L. D. (2011). Demystifying customer brand engagement: Exploring the loyalty nexus. Journal of Marketing Management, 27(7-8), 785-807.

Hollebeek, L. D., \& Chen, T. (2014). Exploring positively- versus negatively-valenced brand engagement: a conceptual model. Journal of Product \& Brand Management, 23(1), $62-$ 74.

Hollebeek, L. D., Conduit, J., \& Brodie, R. J. (2016). Strategic drivers, anticipated and unanticipated outcomes of customer engagement. Journal of Marketing Management, 32(5-6), 393-398.

Hollebeek, L. D., Glynn M. S., \& Brodie R. J. (2014). Consumer brand engagement in social media: Conceptualization, scale development and validation. Journal of Interactive Marketing, 28(2), 149-165.

Hoyer, W. D., Chandy, R., Dorotic, M., Krafft, M., \& Singh, S. S. (2010). Consumer cocreation in new product development. Journal of Service Research, 13(3), 283-296.

Hulland, J. (1999). Use of partial least squares (PLS) in strategic management research: A review of four recent studies. Strategic Management Journal, 20(2), 195-204.

Jaakkola, E., \& Alexander, M. (2014). The Role of Customer Engagement Behavior in Value CoCreation: A Service System Perspective. Journal of Service Research, 17(3), 247-261.

Jain, V., \& Viswanathan, V. (2015). Choosing and using mobile apps: A conceptual framework for Generation Y. Journal of Customer Behaviour, 14(4), 295-309.

Jin, C. H., \& Villegas, J. (2008). Mobile phone users' behaviors: The motivation factors of the mobile phone user. International Journal of Mobile Marketing, 3(2), 4-11.

Kim, J., \& Ah Yu, E. (2016). The holistic brand experience of branded mobile applications affects brand loyalty. Social Behavior and Personality: an international journal, 44 (1), 77-87.

Kim, Y. H., Kim D. J., \& Wachter K. (2013). A study of mobile user engagement (MoEN): Engagement motivations, perceived value, satisfaction, and continued engagement intention. Decision Support Systems, 56 (December), 361-370.

Kim, E., Lin J-S., \& Sung Y. (2013). To app or not to app: Engaging consumers via branded mobile apps. Journal of Interactive Advertising, 13(1), 53-65.

Kim, S. C., Yoon D., \& Kyoung Han E. (2016). Antecedents of mobile app usage among smartphone users. Journal of Marketing Communications, 22(6), 653-670. 
Kim, S.J., Wang, R. J. H. \& Malthouse, E.C. (2015). The effects of adopting and using a brand's mobile application on customers' subsequent purchase behavior. Journal of Interactive Marketing, 31, 28-41.

Kleijnen, M., Ruyter, K. D., \& Wetzels, M. (2007). An assessment of value creation in mobile service delivery and the moderating role of time consciousness. Journal of Retailing, 83(1), 33-46.

Kock, N. (2015). Common method bias in PLS-SEM: A full collinearity assessment approach. International Journal of e-Collaboration (IJeC), 11(4), 1-10.

Kock, N., \& Lynn, G. S. (2012). Research article electronic media variety and virtual team performance: the mediating role of task complexity coping mechanisms. IEEE transactions on professional communication, 55(4), 325-344.

Kock, N., \& Gaskins, L. (2014). The mediating role of voice and accountability in the relationship between Internet diffusion and government corruption in Latin America and Sub-Saharan Africa. Information Technology for Development, 20(1), 23-43.

Kuzel, A. J. (1992). Sampling in qualitative inquiry. In B. F. Crabtree \& W. L. Miller (Eds.), Research methods for primary care, Vol. 3. Doing qualitative research (pp. 31-44). Thousand Oaks, CA, US: Sage Publications, Inc.

Larivière, B., Joosten H., Malthouse E. C., van Birgelen M., Aksoy P., Kunz W. H., and Huang M-H. (2013). Value fusion: The blending of consumer and firm value in the distinct context of mobile technologies and social media. Journal of Service Management, 24(3), 268-293.

Leckie, C, Nyadzayo M. W., \& Johnson L. W. (2016). Antecedents of consumer brand engagement and brand loyalty. Journal of Marketing Management, 32(5-6), 558-578.

Malthouse, E. C., Calder, B. J., Kim, S. J., \& Vandenbosch, M. (2016). Evidence that usergenerated content that produces engagement increases purchase behaviours. Journal of Marketing Management, 32(5-6), 427-444.

Maslowska, E., Malthouse E. C., \& Collinger T. (2016). The customer engagement ecosystem. Journal of Marketing Management, 32(5-6), 469-501. 
McCarthy, J., \& Wright, P. (2004). Technology as experience. Interactions, 11(5), 42-43.

Michaelidou, N., \& Dibb S. (2006). Product involvement: an application in clothing. Journal of Consumer Behaviour, 5(5), 442-453.

Mittal, B. (1995). A comparative analysis of four scales of consumer involvement. Psychology \& Marketing, 12(7), 663-682.

Miyazaki, A. D., \& Fernandez A. (2001). Consumer perceptions of privacy and security risks for online shopping. Journal of Consumer Affairs, 35(1), 27-44.

Mollen, A., \& Wilson, H. (2010). Engagement, telepresence and interactivity in online consumer experience: Reconciling scholastic and managerial perspectives. Journal of Business Research, 63(9-10), 919-925.

Mondi, M., Woods, P., \& Rafi, A. (2008). A'Uses and Gratification Expectancy Model'to predict students"Perceived e-Learning Experience'. Journal of Educational Technology \& Society, 11(2).

Morgan, D. L. (1996). Focus groups. Annual Review of Sociology, 22(1), 129-152.

Morosan, C., \& DeFranco, A. (2015). Disclosing personal information via hotel apps: A privacy calculus perspective. International Journal of Hospitality Management, 47, 120-130.

Morosan, C., \& DeFranco, A. (2016). Modelling guests' intentions to use mobile apps in hotels: The roles of personalization, privacy, and involvement. International Journal of Contemporary Hospitality Management, 28 (9), 1968-1991.

Muntinga, D. G., Moorman, M., \& Smit, E. G. (2011). Introducing COBRAs: Exploring motivations for brand-related social media use. International Journal of advertising, 30(1), 13-46.

Nysveen, H., Pedersen P. E., \& Skard S. E. (2015). A review of mobile services research: Research gaps and suggestions for future research on mobile apps. Centre for Applied Research at NHH (SNF)._Working papers (SNF) [794]. Retrieved from http://hdl.handle.net/11250/279041.

O'Brien, H. L., \& Toms E. G. (2008). What is user engagement? A conceptual framework for defining user engagement with technology. Journal of the American Society for Information Science and Technology, 59(6), 938-55.

Okazaki, S. (2008). Determinant factors of mobile-based word-of-mouth campaign referral among Japanese adolescents. Psychology \& Marketing, 25(8), 714-731. 
----- (2009). Social influence model and electronic word of mouth: PC versus mobile internet. International Journal of Advertising, 28(3), 439-472.

Papacharissi, Z., \& Rubin A. M. (2000). Predictors of Internet use. Journal of Broadcasting \& Electronic Media, 44(2), 175-196.

Ringle, C. M., Wende S., \& Will A. (2005). SmartPLS 2.0 (beta). Hamburg: University of Hamburg. www.smartpls.de.

Schau, H. J., Muñiz Jr A. M., \& E. Arnould J. (2009). How brand community practices create value. Journal of Marketing, 73(5), 30-51.

Schivinski, B., Christodoulides, G., \& Dabrowski, D. (2016). Measuring consumers' engagement with brand-related social-media content. Journal of Advertising Research, 56(1), 64-80.

Seitz, V.A. \& Aldebasi, N.M. (2016). The effectiveness of branded mobile apps on user's brand attitudes and purchase intentions. Review of Economic and Business Studies, 9 (1), 14154.

Shao, G. (2009). Understanding the appeal of user-generated media: a uses and gratification perspective. Internet Research, 19(1), 7-25.

Shankar, V., Venkatesh A., Hofacker C., \& Naik P. (2010). Mobile marketing in the retailing environment: Current insights and future research avenues. Journal of Interactive Marketing, 24(2), 111-120.

Shin, D. H. (2011). Understanding e-book users: Uses and gratification expectancy model. New Media \& Society, 13(2), 260-278.

SmartInsights. (2018). Mobile marketing statistics compilation. Retrieved from http://www.smartinsights.com/mobile-marketing/mobile-marketing-analytics/mobilemarketing-statistics/

Smock, A. D., Ellison, N. B., Lampe, C., \& Wohn, D. Y. (2011). Facebook as a toolkit: A uses and gratification approach to unbundling feature use. Computers in Human Behavior, 27(6), 2322-2329.

Spiggle, S. (1994). Analysis and interpretation of qualitative data in consumer research. Journal of Consumer Research, 21(3), 491-503.

Statista. (2018). Number of apps available in leading app stores as of 1st quarter 2018. Retrieved from https://www.statista.com/statistics/276623/number-of-apps-available-in-leading- 
appstores/; https://www.statista.com/statistics/263794/number-of-downloads-from-theapple-app-store/

Stocchi, L., Guerini, C., and Michaelidou, N. (2017). When are apps worth paying for? An analysis of the market performance of mobile apps. Journal of Advertising Research, 57(3), 260-271.

Sultan, F., \& Rohm A. (2005). The coming era of 'brand in the hand' marketing. MIT Sloan Management Review, 47(1), 83-90.

Sultan, F., Rohm, A. \& Gao, T. (2009). Factors influencing consumer acceptance of mobile marketing: A two-country study. Journal of Interactive Marketing, 23 (4), 308-20.

Sun, T., Youn S., Wu G., \& Kuntaraporn M. (2006). Online word-of-mouth (or mouse): An exploration of its antecedents and consequences. Journal of Computer-Mediated Communication, 11(4), 1104-1127.

Tarute, A., Nikou, S., \& Gatautis, R. (2017). Mobile application driven consumer engagement. Telematics and Informatics, 34(4), 145-156.

Tenenhaus, M., Vinzi V. E., Chatelin Y-M., \& Lauro C. (2005). PLS path modeling. Computational Statistics \& Data Analysis, 48(1), 159-205.

Tojib, D., \& Tsarenko Y. (2012). Post-adoption modeling of advanced mobile service use. Journal of Business Research, 65(7), 922-928.

Van Doorn, J., Lemon K. N., Mittal V., Nass S., Pick D., Pirner P., \& Verhoef P. C. (2010). Customer engagement behavior: Theoretical foundations and research directions. Journal of Service Research, 13(3), 253-266.

Venkatesh, V. L., Thong, J. Y., \& Xu, X. (2012). Consumer acceptance and use of information technology: Extending the unified theory of acceptance and use of technology. MIS Quarterly, 36(1), 157-178.

Vivek, S. D., Beatty, S. E., Dalela, V., \& Morgan, R. M. (2014). A generalized multidimensional scale for measuring customer engagement. Journal of Marketing Theory and Practice, 22(4), 401-420.

Vivek, S. D., Beatty, S. E., \& Morgan, R. M. (2012). Customer engagement: Exploring customer relationships beyond purchase. Journal of Marketing Theory and Practice, 20(2), 122146. 
Viswanathan, V., Hollebeek, L. D., Malthouse, E. C., Maslowska, E., Jung Kim, S., \& Xie, W. (2017). The dynamics of consumer engagement with mobile technologies. Service Science, 9(1), 36-49.

Wang, B., Kim, S. J., \& Malthouse, E. C. (2016). Branded apps and mobile platforms as new tools for advertising. In R. Brown, V. Jones, \& B. M. Wang (Eds.), The new advertising: Branding, content, and consumer relationships in the data-driven social media era Volume 2: New media, new uses, new metrics (pp. 1-39)Santa Barbara, CA: Praeger.

Wirtz, J., Den Ambtman, A., Bloemer, J., Horváth, C., Ramaseshan, B., Van De Klundert, J., ... \& Kandampully, J. (2013). Managing brands and customer engagement in online brand communities. Journal of service Management, 24(3), 223-244.

$\mathrm{Wu}, \mathrm{L}$. (2015). Factors of continually using branded mobile apps: the central role of app engagement. International Journal of Internet Marketing and Advertising, 9(4), 303-320.

Wu, J-H., \& Wang S-C. (2005). What drives mobile commerce? An empirical evaluation of the revised technology acceptance model. Information \& Management, 42(5), 719-729.

Yang, H. C. (2013). Bon Appètit for Apps: Young American consumers' acceptance of mobile applications. Journal of Computer Information Systems, 53(3), 85-96.

Yang, K., \& Jolly, L. D. (2009). The effects of consumer perceived value and subjective norm on mobile data service adoption between American and Korean consumers. Journal of Retailing \& Consumer Services, 16(6), 502-508.

Zaichkowsky, J. L. (1994). The personal involvement inventory: Reduction, revision, and application to advertising. Journal of Advertising, 23(4), 59-70. 


\section{Appendix A}

List of apps included in Study 2

- Facebook

- WhatsApp

- Facebook Messenger

- Google Maps

- YouTube

- Other

- Skype

- Instagram

- Spotify Music

- Snapchat

- 7 Minute Workout Challenge

- Minecraft - Pocket Edition

- Sleep Cycle Alarm Clock

- Fantasy Premier League 14/15

- Heads Up!

- Tinder

- Football Manager Handheld 2014

- Afterlight

- Cut the Rope 2

- Plague Inc.

- Facetune

Incidence of respondents' selection of apps in Study 2

\begin{tabular}{|c|c|c|}
\hline Apps & $\begin{array}{c}\text { nr of respondents } \\
\text { who selected the app }\end{array}$ & \% of sample \\
\hline
\end{tabular}




\begin{tabular}{|l|c|c|}
\hline Facebook & 73 & $29 \%$ \\
WhatsApp & 40 & $16 \%$ \\
Facebook Messenger & 26 & $10 \%$ \\
Google Maps & 23 & $9 \%$ \\
YouTube & 19 & $8 \%$ \\
Other (specify) & 13 & $5 \%$ \\
Skype & 11 & $4 \%$ \\
Instagram & 9 & $4 \%$ \\
Spotify Music & 7 & $3 \%$ \\
Snapchat & 5 & $2 \%$ \\
7 Minute Workout Challenge & 5 & $2 \%$ \\
Minecraft - Pocket Edition & 4 & $2 \%$ \\
Sleep Cycle Alarm Clock & 4 & $2 \%$ \\
Fantasy Premier League 14/15 & 4 & $2 \%$ \\
Heads Up! & 3 & $1 \%$ \\
Tinder & 2 & $1 \%$ \\
Football Manager Handheld 2014 & 2 & $1 \%$ \\
Afterlight & 1 & $0 \%$ \\
Cut the Rope 2 & 1 & $0 \%$ \\
Plague Inc. & 1 & $0 \%$ \\
Facetune & 0 & $0 \%$ \\
\hline
\end{tabular}

